University at Albany, State University of New York

Scholars Archive

Psychology Faculty Scholarship

Psychology

2012

\title{
Women, Alcoholics Anonymous, and Related Mutual Aid Groups: Review and Recommendations for Research
}

\author{
Sarah E. Ullman \\ The University of Illinois at Chicago \\ Cynthia J. Najdowski \\ University at Albany, State University of New York, cnajdowski@albany.edu \\ Ericka B. Adams
}

The University at Albany community has made this article openly available.

Please share how this access benefits you.

Follow this and additional works at: https://scholarsarchive.library.albany.edu/psychology_fac_scholar

Part of the Clinical Psychology Commons, Counseling Commons, Counseling Psychology Commons, Gender and Sexuality Commons, and the Social Psychology Commons

\section{Recommended Citation \\ Ullman, Sarah E.; Najdowski, Cynthia J.; and Adams, Ericka B., "Women, Alcoholics Anonymous, and Related Mutual Aid Groups: Review and Recommendations for Research" (2012). Psychology Faculty Scholarship. 31. \\ https://scholarsarchive.library.albany.edu/psychology_fac_scholar/31}

\section{c) (9) $\odot$}

This work is licensed under a Creative Commons Attribution-No Derivative Works 4.0 International License. This Article is brought to you for free and open access by the Psychology at Scholars Archive. It has been accepted for inclusion in Psychology Faculty Scholarship by an authorized administrator of Scholars Archive.

Please see Terms of Use. For more information, please contact scholarsarchive@albany.edu. 


\title{
PRE-PRINT. This paper is not the copy of record and may not exactly replicate the authoritative document published in the journal.
}

Running head: WOMEN, ALCOHOLICS ANONYMOUS, AND MUTUAL AID GROUPS

11-24-11 Draft

\author{
Women, Alcoholics Anonymous, and Related Mutual Aid Groups: \\ Review and Recommendations for Research \\ Sarah E. Ullman, Ph.D. \\ Cynthia J. Najdowski, M.A. \\ Ericka B. Adams, Ph.D. \\ Department of Criminology, Law, and Justice \\ University of Illinois at Chicago \\ Chicago, Illinois 60607-7140
}
Correspondence should be addressed to Sarah Ullman by mail at Department of Criminology, Law, and Justice, University of Illinois at Chicago, 1007 West Harrison Street, Chicago, IL 60607-7140; by telephone (312-996-6679) or fax (312-996-8355); or by email at seullman@uic.edu.




\begin{abstract}
Recent literature reviews and meta-analyses have supported the effectiveness of Alcoholics Anonymous (AA) in helping members stop drinking and maintain sobriety. Despite the extensive body of research on AA, less attention has focused on differences in the efficacy of the program for and experiences of women as compared to men. Such a focus is warranted given that there are significant gender differences in the development and progression of alcoholism, impact of drinking, and response to treatment. This review synthesizes results of extant research on women in AA and similar mutual aid groups focused on problem drinking to describe the state of knowledge and make suggestions for future research. Critiques of the ability of AA and 12-step programs to address women's needs are also reviewed, as are attempts to respond to those critiques. Understudied issues, including the role of victimization histories (which are more prevalent in women who abuse alcohol), are also discussed.
\end{abstract}


Women, Alcoholics Anonymous, and Related Mutual Aid Groups:

Review and Recommendations for Research

Alcoholics Anonymous (AA) is the most widely available and utilized free form of assistance for people who are attempting to stop drinking and maintain sobriety. AA is a mutual aid group, defined by Schwartz (1961) as an "enterprise in mutual aid, an alliance of individuals who need each other in varying degrees, to work on certain common problems" (p. 266). Recent reviews have shown positive effects of AA on abstinence (Kaskutas, 2009; Kelly, Magill, \& Stout, 2009; McCrady \& Tonigan, 2009). Yet Kownacki and Shadish's (1999) meta-analytic review of 21 controlled studies revealed that, although some components of AA (i.e., having recovering alcoholics as therapists, peer-led self-help therapy groups, teaching the twelve-step process, doing an honest inventory) were associated with positive outcomes (e.g., abstinence at 12 months), those who attended conventional AA meetings generally had worse outcomes than those who received no treatment or alternative treatment. The authors concluded that AA experiences and outcomes are heterogeneous, and it makes little sense to seek omnibus profiles of AA affiliates or outcomes. With that point in mind, it seems important to consider whether one of the major diversity factors, gender, has unique effects in terms of the experiences and/or outcomes of AA participants. Despite the fact that women compose at least one-third of AA participants (AA, 2008), understanding gender differences in AA experiences and outcomes has not been a major focus of study (for an earlier review, see Beckman, 1993). We know that gender differences exist in various aspects of alcohol use, problem drinking, and alcoholism, including amount of alcohol consumption, physiological effects of alcohol, onset of problem drinking/alcoholism, psychosocial aspects of alcoholism, progression of the disease, and efficacy of treatment (Gomes \& Hart, 2009; Greenfield et al., 2007; Keyes \& Hasin, 2008; Nolen- 
Hoeksema, 2004; Nolen-Hoeksema \& Hilt, 2006; Plant, 2008; Timko et al., 2002, 2005;

Wilsnack \& Wilsnack, 1997). For example, some longitudinal studies of treatment efficacy suggest that women may be worse off than men at baseline on drinking and functioning measures (Timko et al., 2002; 2005). But there are also gender differences in help seeking. Women are less likely than men to seek specialty alcohol and drug treatment services, despite being equally likely to benefit from them (for review, see Greenfield et al., 2007). In contrast, women are more likely to utilize informal sources than men, including mutual aid groups and AA (Timko, Moos, Finney, \& Connell, 2002). The importance of studying gender differences in AA use and efficacy is further exemplified by the results of Kaskutas et al.'s (1997) nationally representative longitudinal study: Women were 2.5 times less likely than men to have sought help because of their drinking, but those who did seek help most commonly, and often only, sought it from AA. In a naturalistic longitudinal study of 461 persons with alcohol use disorders, Moos et al (2006) found no gender differences in the frequency or amount of alcohol consumption or number of current drinking problems. However, women reported more current dependence symptoms but fewer lifetime drinking problems than men.

Although some research has evaluated whether the experience and impact of AA differs for women as compared to men, a critical review and assessment of study findings has not yet been conducted. Thus, we review extant research to elucidate what is known about women in AA and what issues should be targeted in future studies. In particular, we synthesize results from studies of gender differences and women's experiences of help seeking in AA (e.g., barriers), affiliation with and commitment to the program (e.g., frequency of attendance, working the steps, having or becoming a sponsor), and various outcomes (e.g., abstinence, mortality). Although we focus on results related to AA, we also review findings related to other mutual aid 
groups targeting and/or used by women problem drinkers (e.g., Women for Sobriety, Moderation Management). Potential mediators and moderators of the effects of AA and mutual aid groups for women are also reviewed. Special issues that differ by gender are examined, including social roles, mental health problems, coping and social support, and victimization experiences, all of which may relate to understanding gender differences in the utilization and impact of AA.

Finally, we discuss critiques of AA for women. Throughout the review, we discuss limitations of existing research and identify directions for future work in this area.

To examine these issues, we conducted a content analysis of 108 studies related to AA and other mutual aid programs for alcohol problems, deeming articles, dissertations, monographs, and books relevant if they (a) analyzed differences between women and men $(n=$ $89)$ or (b) included women only $(n=19)$. We excluded studies that included women but did not report gender differences (of which there were many). Studies of adolescents are included. We completed our search using three methods. First, we used several major online databases (e.g., PsychInfo, Medline, Dissertation Abstracts International) to search for relevant studies using various combinations of the terms gender, women, drinking, help seeking, self-help, mutual help, mutual aid, and Alcoholics Anonymous. We focused predominantly on studies published since 1990 given that earlier reviews of AA already exist (not focused on gender) and most studies examining gender are relatively recent. Second, we searched the tables of contents of alcoholand substance abuse-related journals. Third, we examined the reference sections of all publications retrieved using the prior two methods. Next, we describe these studies and discuss more specifically how they contribute to understanding impact and experiences of AA for women.

Gender Differences in AA Participants' Help Seeking, Affiliation, and Outcomes 
In this section, we review gender differences in women's experiences in AA of help seeking (i.e., process factors, correlates and/or motivating factors, barriers), affiliation and commitment to the program (e.g., frequency of attendance), and outcomes (i.e., drinking, psychosocial adjustment, mortality).

\section{Help Seeking for Problem Drinking}

The first steps to getting help are to recognize that help is needed and to choose to seek help. It is important to understand whether there are (a) gender differences in the process of recognizing the need for and seeking help for problem drinking, (b) unique factors that motivate or facilitate help seeking for women, and/or (c) unique barriers that women must overcome to seek help.

Process factors. Eight studies have tested for gender differences in the process of seeking help from AA (either alone or in addition to formal treatment). Simpson and Tucker's (2002) study of problem drinkers (mentioned earlier) showed that women's earlier recognition and seeking of help for their drinking problem than men's did not appear to impact their outcomes (i.e., abstinent or not), however this study had a retrospective design, smaller sample with less power than Timko et al.'s (2000) study showing earlier recognition did positively affect women's drinking outcomes.

Raimo et al.'s (1999) semi-structured interviews of 3572 alcohol-dependent subjects (35\% women) showed that women were more likely than men to attend AA only, as opposed to other forms of treatment in both outpatient and inpatient samples studied. In contrast, Simpson and Tucker (2002) studied 101 current and former problem drinkers (34\% women) who were recruited from the community and found that, although women tended to recognize they had a problem and sought treatment earlier than did men, women and men did not differ in whether 
they ultimately recognized they had a problem with drinking or whether they sought help from AA for it. This is consistent with other studies showing no gender differences in help seeking from AA. In Kaskutas, Weisner, Lee, and Humphreys' (1999) sample of 791 adults entering substance abuse treatment programs (33\% women), women and men were just as likely to report past or current AA attendance. Similarly, Harris et al.'s (2003) interviews of 150 patients entering inpatient addiction treatment ( $25 \%$ women) revealed that women and men were equally likely to have attended AA in their lifetimes and in the past year. Yet, even though Room and Greenfield's (1993) national probability survey of 2,058 adults (52\% women) showed that equal proportions of women and men had attended an AA meeting, women were outnumbered by men in attendance at other support or therapy groups for alcohol problems. This is in line with the results of Weisner et al.'s (1995) analysis of the Alcohol Research Group's probability surveys of the U.S. household population conducted in 1979 ( $n=1772,57 \%$ women $), 1984$ ( $n=5221$, $60 \%$ women), and 1990 ( $n=2058,58 \%$ women). At all three time points, higher proportions of both women and men reported going to AA than to any other single type of program but, over time, the ratio of women to men in AA decreased (from 1:2.2 to 1:3.1). In addition, Moos et al.'s (2004) study of 1,291 community-residing adults (41\% women) who had recently consumed alcohol revealed that, even though drinking-related help seeking was relatively rare among both women and men, at baseline, significantly fewer women (1\%) than men (3\%) had sought help for drinking problems in the last year. These percentages and gender differences remained stable for 10 years. In Horstmann and Tonigan's (2000) study of 47 AA members (38\% women), women were more likely to receive other professional help for emotional or alcohol problems. Hillhouse and Fiorentine's (2001) interviews of 356 participants in outpatient alcohol and drug treatment programs (55\% women) revealed that, even after 2 years, women were equally likely 
to attend 12-step programs and to recover (e.g., be alcohol and drug abstinent) as were men. Slaymaker and Owen (2006) studied 212 employed adults (51\% women) entering a residential treatment program. Most (94\%) of the sample had attended at least one AA or Narcotics Anonymous (NA; a 12-step program modeled after AA that focuses on drug addiction rather than alcohol addiction) meeting in the year after their discharge, with no difference noted between women and men in number of meetings attended.

Results such as this suggest that future research should focus on understanding whether there are gender differences in the types of barriers to formal alcohol treatment and the role of informal help such as AA.

Correlates and/or motivating factors. Factors leading women alcoholics to seek treatment may differ from those encountered by men (see National Institute on Alcohol Abuse and Alcoholism, 1990, for summary). Women are more likely than men to seek alcohol treatment because of family problems, and they often are encouraged to do so by parents or children (Gomberg, 1974). In contrast, men usually are encouraged by their wives and are more likely to reach treatment through employee assistance programs or the criminal justice system than are women (Roman, 1988).

Simpson and Tucker (2002) also found that compared to men, women had a shorter lag between experiencing relationship problems, tolerance/withdrawal, job/financial problems, legal problems, and neurological problems and initial help seeking (either treatment or AA). Perhaps women recognized these issues were related to their problem drinking or were more sensitized to these problems and predisposed to reach out for help than men (Taylor, 2007). However, George and Tucker (1996) found no gender differences in factors motivating AA participation, including family problems due to alcohol and family encouragement. Other analyses of these data found no 
gender differences in various incentives (e.g., encouragement/problem with family, friends, employers, AA features, insurance to alcoholism treatment (Tucker, 1995).

Room and Greenfield (1993) found that men were over three times as likely as women to report having gone to AA for an alcohol problem of their own. Some of women's extra attendance at AA meetings is potentially due to problems related to others' drinking, as women were more likely than men to have attended meetings of Al-Anon (a 12-step mutual aid group for families of alcoholics) and adult child of alcoholics (ACOA) groups. These national data suggested that only lifetime utilization differs significantly by gender, with greater attendance of AA by men and of co-alcoholic and other 12-step groups by women and no significant gender difference in past 12-month usage. Over one-third of women and about one-quarter of men who saw a therapist or counselor in the last year about a non-alcohol problem had also attended a 12step or other support or therapy group. Finally, in two national samples of women, having a network of trusted friends to talk to about personal problems predicted AA attendance (Witbrodt \& Romelsjo, 2010), suggesting that social networks can facilitate going to AA in women.

Barriers. We found only 2 studies examining gender differences in barriers to AA participation. In George and Tucker’s (1996) study of 45 problem drinkers (38\% women) recruited from the community who had recently entered outpatient alcoholism treatment or AA, overall, women reported more barriers to AA participation (e.g., stigma, access) than did men. Women and men did not differ, however, in their ratings of how much these barriers thwarted treatment. In a recent probability sample of 733 at-risk drinkers from $33 \%$ women), Small et al. (2010) found that despite receiving greater emotional support for alcohol problems and help seeking from their networks than men, women and men received similar levels of tangible aid (e.g., financial assistance) from their support networks. Compared to men, women had more 
financial barriers to accessing healthcare services, poorer mental health (including, e.g., more depression), worse social functioning, and more drinkers in their social networks, and they also perceived greater stigma from their communities. It is important for research to determine how these types of barriers can be countered for women, because women also reported being less willing than men to participate in 12-Step programs. There were no gender differences in recent help seeking overall for either substance abuse problems or current drug use.

\section{Summary.}

Taken together, the few studies addressing gender and help seeking suggest that motivating factors and barriers to treatment may differ by gender. However, more research is needed because many of the existing studies are small and descriptive in nature, and results are inconsistent. Future studies could include surveys and qualitative interviews of communitydwelling women problem drinkers which focus on their experiences of help seeking for their drinking, including why they sought help and whether they faced any barriers to obtaining help.

Even so, results suggest there are some reliable gender differences in help seeking for problem drinking. Despite being more likely to seek help earlier than men, women appear to face greater numbers of barriers and perhaps some unique barriers to being able to enter treatment. For example, in past research conducted prior to the scope of this review, lack of childcare was one of the most frequently reported barriers to treatment for alcoholic women (Wilsnack, 1982). Although neither George and Tucker (1996) nor Small et al. (2010) examined this potential barrier, future research should consider the influence of childcare access and other issues (e.g., caring for sick or elderly family members) that might make it more difficult for women than men to seek help, given their greater likelihood of assuming caretaker roles. Finally, research is needed on how to facilitate women's access to help for problem drinking, taking gender 
differences in motivating factors and barriers into account.

\section{Affiliation with and Commitment to AA}

Once people do seek help from AA, are there gender differences in affiliation and commitment to the program? We examine this question in this section. In research, affiliation is usually defined as the number of AA meetings attended (Reigle \& Dowd, 2004). In reality, affiliation is a process that develops over time. As such, we recognize that factors such as reading the AA literature (e.g., the "Big Book" which lays out the AA program) and having a sponsor and close friends in AA are important aspects of affiliation (Reigle \& Dowd, 2004). Commitment has been conceptualized as the degree to which one is invested in the program and may involve, for example, length of time in the program, number of steps worked, and extent of service work done on behalf of AA (e.g., being a sponsor or meeting leader) (Tonigan, Connors, $\&$ Miller, 1996). Despite use of these terms in the literature, researchers have not made clear conceptual and empirical distinctions between affiliation and commitment in AA. Therefore, both terms are discussed here and studies are not grouped according to whether authors used either of these specific terms.

There was no gender difference in frequency of AA attendance over the past year in Humphreys, Phibbs, and Moos' (1996) sample of 218 problem drinkers (56\% women) recruited through alcoholism information and referral services and detoxification centers. Similarly, in the Harris et al. (2003) study described previously, women and men attended meetings with similar frequencies in their lifetimes, although women had attended fewer meetings than men in the past year. Horstmann and Tonigan's (2000) survey of 47 AA members (38\% women) also revealed no gender differences in AA participation measures (i.e., attended 5+ meetings in a week, had a sponsor, celebrated an AA birthday, called someone in AA for help, read 12-step literature), but 
women were less likely than men to report ever having been a sponsor. Gomes and Hart (2009) surveyed 78 alcoholic patients (31\% women) who had completed an inpatient treatment program based on the 12 steps of AA an average of 2 years earlier. There were no differences between women and men in recovery on daily AA maintenance practices (e.g., praying, attending meetings, working the steps). Women were less likely to have a sponsor, but those who did had more daily sponsor contact than men. Slaymaker and Owen (2006) studied 212 employed adults (51\% women) entering a residential treatment program (virtually all of whom had been to AA or NA) and found no gender differences in whether they had a sponsor. Finally, DelBoca and Mattson (2002) found that, among 1,252 clients from outpatient treatment settings (21\% women), women attended AA meetings as often as men, but among 774 aftercare clients (20\% women), women attended more AA meetings and were more involved in AA.

A number of large-scale longitudinal studies have explored whether there are gender differences in affiliation with and commitment to AA. Moos et al. (2006) studied 461 adults with alcohol use disorders (50\% women), assessed at baseline and 1, 8 and 16 years later. Compared to men, women were more likely to participate in AA and participated in more meetings in the first year. Although women were still more likely to participate in AA after 8 years, there was no gender difference in the number of meetings attended, and all gender differences were nonsignificant after 16 years.

Two studies found no gender differences. Timko et al. (2005) found that, among 466 individuals with alcohol use disorders (49\% women), women and men did not differ in whether they received professional treatment or attended AA, but women were in professional treatment longer and were more likely to participate in AA during the first follow-up year. A trend was found toward more frequent meeting attendance in women at a 6-month follow-up in Weiss et 
al.'s (2000) sample of 487 cocaine-dependent hospital patients (23\% women). In one of several studies using a sample of 473 individuals seeking help for alcohol use disorders for the first time (50\% women), Moos and Moos (2004a) found women stayed in treatment and AA longer than men. Witbrodt and Romelsjo (2010) studied 1,525 Swedes (43\% women) and 926 Americans (38\% women) in representative treatment samples. There were no gender differences in predictors of meeting attendance. Pre-treatment AA exposure and abstinence as a treatment goal predicted AA affiliation one year later for both genders. Bodin (2006) studied 152 individuals entering a treatment program (26\% women) and found that women had higher affiliation with AA than men in terms of meeting attendance, reading AA literature, and calling an AA member for help. Gender-specific analyses showed that women's likelihood of affiliation at a 1-year follow-up increased if their treatment goal of baseline was abstinence, whereas it decreased if their goal was drinking reduction. These same relationships were observed for men, but additional variables also predicted affiliation for men (i.e., pre-treatment AA exposure, more financial support from work, more program aftercare sessions, treatment completion, and higher baseline levels of alcohol-related harm

Summary. To summarize, research on gender differences in AA affiliation and commitment have yielded mixed findings. There are no clear patterns across studies that suggest how specific study characteristics might relate to specific results, and inconsistent findings might be explained, once again, by the fact that many of the studies are small, descriptive, and exploratory in nature. Even so, because more studies than not indicate that there are at least some gender differences in AA affiliation and commitment to the program, more systematic largescale research is warranted to examine these differences. This is particularly important given that some studies show that women are less likely than men to affiliate with and be committed to AA. 
Yet, even if overall rates of affiliation with and commitment to AA are similar for women and men or greater for women than men, research is still needed to understand whether the pathways by which women and men engage in the program differ. For example, studies suggesting that women are more involved in AA than men could be explained by the finding that women in AA have more severe histories of alcohol problems compared to men in the program (Timko et al., 2002; 2005). Understanding whether there are gender differences in the processes of affiliating with and committing to AA may be useful for determining whether aspects can be uniquely modified for women to increase their likelihood of achieving successful outcomes. Research is also needed to determine whether women and men have different treatment goals or whether these goals mediate the effect of gender on likelihood of AA affiliation and persistence over time.

\section{AA-Related Outcomes}

Several outcomes of AA have been studied, including drinking, psychosocial adjustment, and mortality. Next, we review research focused on gender differences in the impact of AA on these outcomes.

Drinking. Various non-experimental studies have examined whether gender moderates the impact of AA involvement on drinking outcomes (e.g., alcohol consumption, alcohol problems, alcohol-related help seeking). Some studies indicate that women have better drinking outcomes than men after AA, but more often studies have mixed and/or complicated results. Research by Timko et al. (2000, 2002, 2005) showed that, among 466 untreated problem drinkers (49\% women), AA attendance had a stronger effect on positive drinking outcomes for women than men after 8 years. Brown et al. (2002) followed a sample of 133 adults entering treatment (33\% women) for 6 months, and found that women had better alcohol outcomes with 
12-step-facilitation aftercare (e.g., a 12-step based treatment) than those exposed to structured relapse-prevention aftercare (e.g., traditional behavioral treatment). Moos et al. also considered the effects of trying to cut down on drinking and receiving help for drinking. Among men, but not women, participating in AA predicted a lower likelihood of concomitants and problems, but women had fewer alcohol dependence symptoms and higher self-efficacy than men. Aharon (2000) conducted a 3-year follow-up study of 228 substance-abusing clients (23\% women) who entered a private addiction rehabilitation hospital for residential treatment. AA attendance was related to better recovery status for all clients. In a study of 60 women alcoholics who were new members of AA, Freeman (2001) found that $77 \%$ of variance in days abstinent was explained by women's attendance at AA meetings and time spent with a sponsor, and time spent with a therapist, suggesting specific aspects of affiliation and support seeking need to be assessed to understand women's likelihood of abstinence.

In contrast, other research has found no gender differences in AA outcomes. Delucchi and Kaskutas (2010) studied a random community sample of 672 problem and dependent drinkers (39\% women) and found that AA was related to less drinking over 11 years for all participants, regardless of gender. Ammon et al. (1999) conducted a 7-year longitudinal study of 926 alcoholics who were just entering treatment (39\% women) and 672 dependent and problem drinkers from the general population who had not had treatment in the past year (39\% women). AA attendance was related to decreased alcohol consumption over time for both women and men. Gomes and Hart (2009) surveyed 78 recovering alcoholics (31\% women) 2 years after discharge from an inpatient treatment program that emphasized AA practices of abstinence, spirituality, and the 12 steps. They found no gender differences in number of alcoholic slips since treatment or current length of sobriety. Schuckit et al. (1997) found no interaction effects 
between gender and having attended AA on abstinence in a sample of 1,853 alcohol-dependent participants (32\% women). AA attendance was related to less drinking and abstinence for both women and men over 3 years in Kelly et al.'s (2006) sample of 227 alcohol-dependent outpatients (27\% women). Moos et al. (2006) assessed drinking-related outcomes of AA attendance in 461 adults with alcohol use disorders (50\% women) at four time points: Baseline and 1, 8, and 16 years later. Compared to men, women had higher rates of remission from drinking than men that were related to continuing longer in AA. Moos et al (2006) found no gender differences in the frequency or amount of alcohol consumption or number of current drinking problems. However, women reported more current dependence symptoms but fewer lifetime drinking problems than men.

Psychosocial factors. Few studies have examined the impact of AA on psychosocial factors (e.g., quality of life, stress, coping, social support, self-efficacy), some of which may mediate the effects of AA on drinking outcomes. Timko et al. (2005) examined effects of participation in professional treatment and AA on social context and coping strategies in 466 individuals with alcohol use disorders (49\% women). Regardless of gender, longer duration of AA attendance during the first year and 8 years later related to having more resources from friends, more approach coping, and less drinking to cope, all of which related to improved drinking outcomes.

Two other studies of AA-related recovery suggest that there are no differences between women and men in quality of life or stress. Specifically, in a cross-sectional study, Laudet (2006) found no gender differences in quality of life or stress level among 353 recovering persons in AA and other 12 -step programs (44\% women), most of who were inner-city ethnic minority drug abusers. In Humphreys et al.’s (1994) sample of 439 problem drinkers (50\% women), life 
stressors (e.g., financial, health, home, neighborhood, family, partner, friend) and resources from different social network members (e.g., work, partner, family, friend) impacted AA involvement, but women and men did not differ in whether they experienced these stressors at a 3-year followup, although some resources (e.g., friend and extended family support) differed by gender. Cellar et al. (2008) studied 420 previously untreated individuals who were seeking treatment for alcohol use disorders (51\% women). After 16 years, women experienced more increased alcohol-related self-efficacy than men, which is thought to be important for increasing abstinence. Whereas this study did not indicate whether self-efficacy was related to less drinking over time, it revealed that predictors of self-efficacy after 1 year included improvement from baseline in heavy drinking, alcohol-related problems, depression, impulsivity, avoidance coping, social support from friends, and longer duration of participation in AA. Female gender during the first year predicted improvement in self-efficacy over 16 years. This suggests that one particular avenue to study further for improving women's drinking outcomes may be improving their self-efficacy. AA may improve self-efficacy, which may reduce negative drinking outcomes. Whether such effects of AA are moderated by gender also needs study.

Suire and Bothwell (2006) studied 100 alcoholics (44\% women) solicited outside of AA meetings for a questionnaire study on attitudes of alcoholics towards themselves and others according to whether they had worked the 12 steps. Alcoholics who had been able to stay in the program and work through all 12 steps had lower levels of interpersonal insecurity than those who were just beginning to work the steps. No significant differences were found in social potency between those who had completed the steps and those who had not and findings did not differ by gender.

Mortality. Four studies examined AA and gender in relation to mortality. Masudomi et 
al. (2004) found that involvement with self-help groups (e.g., AA) reduced risk of mortality equally for women and men in a sample of 375 adults in Tokyo (14\% women). Similarly, Mann (2006) reported that AA participation related to lower suicide rates in both women and men in Ontario. Other studies suggest that AA may affect mortality differently for women and men. In the only longitudinal investigation of AA effects on mortality, Timko et al. (2006) tracked 628 individuals with alcohol use disorders who were seeking help for the first time (47\% women). Over 16 years, of individuals for whom cause of death was known, $68 \%$ died of alcohol-related causes, with women were likely to die than men.

\section{Summary of Outcomes}

To summarize, many studies of AA show positive effects on drinking outcomes for both women and men, and the few studies that do show significant gender differences tend to suggest that attending AA results in less drinking and more abstinence for women than for men. Little research has attempted to uncover the basis of these differences, but reasons could be related to pre-existing differences between women and men who go to AA (e.g., pathway into the program, readiness to change) or other gender differences in drinking patterns, coping, seeking of other forms of informal and formal social support, degree of involvement, and/or other effects of AA participation. For instance, women may have better treatment outcomes because they tend to seek help sooner than men (Simpson \& Tucker, 2002). Testing these possibilities would be a fruitful avenue for future research. The lack of a definitive answer regarding whether gender moderates the impact of AA on drinking could be due to methodological limitations of studies, as suggested previously, and/or methodological differences across studies. For example, differences in samples could contribute to inconsistent findings, as suggested by the fact that studies show fewer gender differences in AA's effects when participants are inpatients as 
compared to outpatients, perhaps due to greater severity of alcohol problems and/or homogeneity of persons in inpatient treatment. Gender, AA, and sample type might all interact to affect drinking outcomes. Thus, it is important to consider study characteristics when interpreting results. Finally, research has also shown gender differences in other outcomes, such as those related to employment (which AA affected more positively for men than women), so it will be important for studies to focus on other consequences (Timko et al., 2000; 2002). The few studies that have examined AA and gender differences in mortality outcomes show that AA is related to less suicide for both genders, but fewer alcohol-related deaths for women than men. Given that AA reduces drinking and having fewer alcohol dependence symptoms was related to less mortality in one longitudinal study (Timko et al., 2006), it is possible that AA indirectly reduces the odds of alcohol-related deaths for women and men by reducing drinking. However, research to date has not shown this conclusively.

\section{AA and Other Mutual Aid/Self-Help Programs}

Next, we review research that has examined gender differences in experiences and impact of other mutual aid programs for reducing problem drinking.

\section{Help-Seeking and Affiliation}

Studies reveal similar trends in AA attendance among women and men, and this appears to be the case for attendance at other kinds of mutual aid groups, too. Most studies, however, do not clearly separate AA from other mutual aid groups, partly because help seeking from other groups is relatively rare.

Several cross-sectional studies of help seeking have used population-based samples. Ogborne and Dewit (1999) studied a representative sample of 10,171 Canadian adults who reported that they had consumed alcohol at some time in their lives (52\% women). Only $1 \%$ of 
participants had sought help from AA, but attendance at other support groups was so infrequent and variable that the authors chose not to report on it. The majority of women and men who had sought help had done so only from AA. Hasin and Grant (1995) investigated the prevalence and characteristics associated with histories of seeking help for alcohol problems from AA or professional or informal sources of help in a sample of 8,057 former drinkers (51\% women). They found no gender differences in AA attendance or help seeking from other informal (e.g., non-AA) sources. Allen et al.’s (1998) study of 3,695 adults referred for alcohol evaluation or treatment (48\% women) revealed that women did not ask for help for drinking from AA but men did.

Kaskutas' (1996) study of Women for Sobriety members showed that almost all survey respondents received professional help for their alcohol problems and professionals directed $80 \%$ to AA (only $40 \%$ to Women for Sobriety). About $40 \%$ of the women tried either professional treatment or mutual help initially to help them quit drinking. Klaw (2003) surveyed 445 problem drinkers (53\% women) who called Moderation Management's national information and referral line and found that women callers said they needed support more than men. Klaw (2000) found that women posted comments in an online support group more than did men (72\% versus $28 \%)$, which contrasts with the fact that self-help groups like AA contain mostly men (AA, 2008).

Several longitudinal studies of treatment-seeking populations have yielded mixed results with regard to gender differences in the sources from which adults seek help for alcohol problems. Kaskutas et al. (1997) examined predictors of drinking-related help seeking from a variety of sources (e.g., AA, physician, treatment agency, anyone at all) over 8 years among a general population sample of 2,234 individuals (53\% women). Of 235 respondents $(\mathrm{N}=79$ female) who had already experienced 3 or more dependence-related symptoms at baseline, 
although gender differences in help seeking from specific sources were not examined, gender did not affect help seeking overall, even after controlling for other demographic characteristics. Two other longitudinal studies showed no gender differences in mutual aid group use. Kertesz et al. (2006) found no gender difference in mutual help group utilization (i.e., self-reported attendance at AA, NA, or "self-help groups") over 2 years among 274 individuals recruited at an urban detoxification unit as part of a randomized clinical trial (59\% women). In conclusion, most studies show no gender differences in help seeking from mutual aid groups. This may partly be due to men and women using different sources of help for different types of problems.

Women-only samples. Several studies have looked at help seeking in samples of women only. For instance, Kaskutas (1996) studied help seeking in 571 members of Women for Sobriety, a women-only self-help option oriented toward positive thinking and behavior modification. Women often attempted to stop drinking using strategies other than help seeking (e.g., willpower, reducing amount or context of drinking, praying, reading, isolating, avoiding drinking settings), but physical, behavioral, and social effects of drinking led women to seek help (e.g., counseling, hospital, other program). Twenty percent of women cited such problems as the reason they went to AA, whereas only $6 \%$ cited these problems as leading them to Women for Sobriety. In a separate analysis of the same sample, Kaskutas et al. (1997) studied reasons for attending Women for Sobriety as compared to AA. Women reported attending both programs for support. Women attended Women for Sobriety for the program philosophy, all-women forums, and the safe environment at meetings, whereas the most popular reason for attending AA was the belief that one would not drink as long as one continues to go to AA. Thus, AA is seen as an insurance policy against relapse, powerfully motivating Women for Sobriety members to continue to attend AA. Other reasons for going to AA included the need for many meetings to 
stay sober, easy availability of AA meetings, and the ability to make and maintain friends. Many attended AA to learn from others and because they valued the sharing in meetings and liked the program (e.g., the 12 steps, spiritual focus, structure of meetings, mixed-gender meetings, literature). Fewer attended due to being mandated to do so (e.g., by a court or treatment system) or strongly recommended to go (e.g., by minister, friend, or counselor). Reasons for not going to AA included perceptions of not fitting into AA, disagreement with program principles, and viewing AA as either too negative (e.g., drunkalogs (e.g., stories about drinking), spiritual, maleoriented, punitive, shame/guilt-inducing, rigid, or authoritarian).

Finally, Copeland et al. (1993) compared the effects of women's only versus mixedgender treatment services in 160 women seeking treatment for alcohol- and drug-associated problems. Prior to admission, $50 \%$ of women had little or no previous involvement with 12-step programs, but $25 \%$ had attended more than 80 AA and/or NA meetings. At a 6-month follow-up, women were just as likely to attend AA/NA meetings if they were received specialist women's services (67\%) as compared to traditional mixed-gender services (62\%), each of which involved introduction to 12-step programs as one of their treatment components.

These studies are interesting as they point to possible mechanisms for women's attendance at different mutual aid groups and attaining sobriety (e.g., AA's abstinence focus, Women for Sobriety's positive women focus). These studies provide in-depth understanding of women's experiences in AA and women for Sobriety and may add to what the gender comparison studies reveal, by suggesting mechanisms that explain why gender differences exist in some cases.

\section{Affiliation}

Several studies have shown no gender differences in attendance of mutual aid group 
meetings. Davis and Jason (2005) studied 87 current residents (44\% women) of Oxford House, which are self-run, community-based recovery homes. Women and men attended 12-step meetings with equal frequency. Westermeyer, Myatt, Aarts, and Thuras (2001) found no gender difference in the likelihood of self-help group attendance in a sample of 642 adults presenting for treatment for substance use disorders at two alcohol and drug treatment centers (43\% women). Connors and Dermen (1996) described results of a survey of 158 participants (27\% female) in Secular Organizations for Sobriety (SOS), an alternative recovery method for alcoholics or drug addicts uncomfortable with the spiritual content of more widely available 12-step groups. Thirty percent of participants were attending AA meetings simultaneously, a rate that did not differ by gender. Tomasson and Vaglum's (1998) study of 341 patients discharged from treatment seeking aftercare (30\% women) also revealed no gender difference in number of AA meetings attended. Kelly et al. (2006) found no gender difference in mutual aid group participation in 227 alcoholdependent outpatients ( $27 \%$ women) 1 year after enrollment in a randomized-controlled case monitoring trial.

Some research shows gender differences in modality of participation in 12-step groups. Humphreys and Klaw (2001) studied effects of participating in Moderation Management meetings, a program geared towards persons with nondependent problem drinking who wish to moderate their drinking. Comparisons were made in a sample of 117 clients (38\% women) between three types of participation: online only $(n=73)$, in person only $(n=62)$, or both online and in person $(n=4)$. Results revealed that, overall, this treatment attracted women more than men. More online-only members were women than men, and women reported choosing the online option more than in-person meetings (60 versus $40 \%$ ) because they (a) found writing about their feelings and experiences easier than speaking in front of a group and (b) wanted 
access to this treatment at any time of day. Humphreys, Mavis, and Stoffelmayr (1994) studied 158 persons over 1 year after substance abuse treatment women were more likely to drop out than were men. These studies suggest more research is needed to identify and address barriers unique to women that may impede their initial participation or continuation in mutual aid groups.

\section{Outcomes}

Several longitudinal studies have examined gender differences in various outcomes (e.g., drinking, drug use) of mutual aid group attendance.

Drinking. Tucker and Gladsjo (1993) studied 126 problem drinkers (27\% women) who varied in their help-seeking history (none, AA only, or AA plus formal treatment) and current drinking status (abstinent more than 6 months or engaging in problem drinking). Regardless of gender, participants who attended AA plus treatment consumed alcohol on fewer days per month than did those who attended AA only or had not sought help, and the latter groups did not differ from each other on alcohol consumption. Riper, Kramer, Keuken, et al. (2008) conducted a randomized trial with 261 adult problem drinkers from the Dutch general population (49\% women) to examine the effectiveness of Drinking Less, a free-access, interactive, Web-based self-help intervention without therapist guidance that is available 24 hours a day every day for problem drinkers who want to reduce their alcohol consumption. The program also includes access to a moderated peer-to-peer discussion forum. Drinking Less reduced alcohol consumption equally for women and men when assessed at 6 months post-intervention, but at 12 months post-intervention, women had reduced their alcohol consumption to a greater extent than had men. Connors et al.’s (1998) study of 142 alcohol abusing or dependent clients entering inpatient and outpatient alcohol treatment programs (46\% women) revealed no gender difference in the use or influence of self-help groups as a method for achieving or maintaining abstinence 
over 1 year. Finally, Kaskutas (1996) found that Women for Sobriety members not attending AA also took longer to achieve sobriety than those also going to AA after they realized they had a problem and needed help.

Other substance abuse. Kelly et al. (2006) showed that gender did not interact with mutual-help participation to affect substance use outcomes. Tucker and Gladsjo (1993) found that problem drinkers who attended AA plus treatment used more kinds of nonprescribed drugs (e.g., marijuana, cocaine) than those who attended AA only or had no assistance, and the latter groups did not differ.

Women-only studies. Smith (1992) studied 86 women seeking help from either AA, an outpatient hospital alcohol treatment unit, or a local council group for alcoholism in the community. The council group had the least sobriety and most women still drinking, but they drank a lower amount of alcohol than those still drinking in the AA group. Otherwise there were no differences between groups. Kaskutas (1996) found that women who went to both AA and some other form of professional help achieved sobriety faster than other women. Women for Sobriety members reported finding the group therapy very helpful in their quitting drinking. Women for Sobriety members who went to AA achieved more sobriety and fewer relapses than women who attended Women for Sobriety only. Studies of women are consistent with other studies showing AA plus some form of other treatment is related to greater sobriety. This research suggests that women may benefit from AA in combination with other forms of help, whereas perhaps AA suffices for men. Studies are needed to better understand not only the role of AA and mutual aid groups on drinking, but also how additional forms of help seeking may work on concert to perhaps help women more than men.

\section{Summary}


Overall, studies of mutual aid groups show few gender differences in drinking outcomes, but they are few in number and have small samples, as is the case with women-only studies. The only two longitudinal studies showed conflicting results. Because gender differences in program efficacy might not be apparent immediately, this highlights the importance of more longitudinal studies in this area.

In summary, clearly many women attend not only AA but also other mutual support groups and professional treatment. Other programs may be helpful to problem drinkers when used alone or in conjunction with AA, although they do appear to differ from AA. For example, they may not focus on abstinence, and some may not have the same gender biases of AA (e.g., Women for Sobriety), all of which may attract women and/or address their unique needs. Most alternative programs are not as widely available as AA and they appear to be used frequently in conjunction with AA. Timko (2008) recently concluded that women may integrate more easily into AA than men and that they benefit as much as men, despite critiques of AA being maleoriented discussed earlier. She also argued, however, that there is still inadequate information about effects of AA on women, including (a) how much women attend women-only meetings which may influence outcomes of AA and (b) to what extent other organizations geared toward women (e.g., Women for Sobriety) may be more helpful to women than AA (Kaskutas, 1996). There are similarities between AA and other mutual aid groups in providing social support and tools to individuals for combating problem drinking in the community. A major distinction is that AA is focused on abstinence and encourages self-labeling of members as "alcoholics," whereas other groups (e.g., Moderation Management, Women for Sobriety) encourage moderated/reduced drinking (e.g., harm reduction) and do not include a norm of self-labeling as alcoholic. This distinction may be more important for women than for men, because the 
alcoholic label is still more stigmatizing for women in our society.

\section{Moderators and Mediators of the Effects of AA and Mutual Aid Groups}

Various mediators and moderators may relate to AA and its impact differently for women and men. This section reviews studies addressing age, race, sexual orientation, interpersonal/relational factors, spirituality, mental health/illness, criminal justice/legal problems, and victimization history.

Age

Some cross-sectional research has examined whether age differences exist for women and men in use of AA and mutual aid groups. In Room and Greenfield's (1993) national probability sample, gender and age interacted to influence patterns of lifetime and 12-month use of help sources. For example, for women more than men, 12-step lifetime meeting attendance is more common among younger than among middle-aged adults, and past year attendance was higher in younger and middle-aged adults than in older adults. Older adults did not differ from the other age groups in attendance. Regardless of gender, older persons were also less likely than middle-aged or young adults to have been to a therapist or counselor, but not a therapy group. Looking within age groups, men have higher past-year AA attendance than women among younger and older respondents, while for women, AA attendance peaks in middle age. Mann (2005) studied cirrhosis mortality rates in relation to AA participation rates and alcohol consumption in Ontario and found that AA participation and lower alcohol consumption were each related to lower mortality rates, except for among older women and middle-aged men. Satre et al. (2004) studied 925 adults admitted over 2 years to treatment at a chemical dependency recovery program (43\% women) and found among older adults, there were no gender differences in AA affiliation, though findings regarding gender differences in other age groups were not reported. 
Overall, AA use does seem to differ by age in unique ways for women and men, but without longitudinal studies of multiple age groups/cohorts, these differences may be hard to fully understand. Rychtarik et al (2000) found that demographic and AA attendance variables predicted years since last drinking episode. Ullman and Najdowski (2010) studied correlates of alcohol-related help seeking from various sources (i.e., from AA, hospital, mental health, criminal justice, others) in 526 women sexual assault survivors who were current problem drinkers. Older women survivors were more likely to seek alcohol-related help than were their younger counterparts. Other studies showed that gender differences in frequency of meeting attendance were observed among older but not younger alcohol-dependent outpatients from a chemical dependency program at 6 months (Satre et al., 2004) and up to 5 years in the same sample (Weisner et al., 2003).

A few studies have examined gender and affiliation with AA among adolescents. Chi et al. (2009) studied 419 adolescents (34\% girls) from four chemical dependency programs using telephone interviews. Girls who attended AA had higher alcohol and drug abstinence rates than boys after 3 years. Homan and LeCroy (1996) examined characteristics of 70 adolescents, half of who were affiliated with AA (60\% girls) and discriminant function analyses showed that gender did not differentiate AA users from non-users. Kelly et al. (2008) studied two clinical samples of youth ( $n=74,62 \%$ girls, and $n=377,49 \%$ girls) by asking about their perceptions of and experiences with AA/NA. In one sample, girls and minority youths were not found to differ from boys or Caucasian youths, respectively, in their prior participation in AA/NA programs. Winters (2000) compared drug use outcomes data at 6 and 12 months post-treatment among three groups of adolescents: those who completed treatment, those who did not, and those on a waiting list. Also, among 179 treatment completers (44\% women), residential and outpatient samples were 
compared on outcomes. Gender and age did not interact with outcome findings. Whereas age and gender were not related to the general outcome variables, the percentage of adolescent girls who reported a full year of abstinence from alcohol was greater compared to boys. Similar null findings have been reported in studies of adolescents: Kelly, Myers, and Brown (2000) studied 100 adolescent alcoholics (60\% girls) in inpatient treatment and found 12-step group attendance was related to better substance abuse outcomes regardless of gender at 6 months post treatment. To summarize, there are few studies of adolescents and gender differences in AA affiliation, so more work is needed in this subpopulation. It appears that older women may be more likely to seek help, but when younger women do seek help, they are more likely to be abstinent than men. Thus, early interventions tailed to identifying and intervening to stop girls' heavy and/or problem drinking may be warranted.

\section{Race and Ethnicity}

Race and ethnicity, or factors associated with race and ethnicity (e.g., acculturation), also might play a role in understanding women's involvement in and effects of AA and mutual aid groups, but this has only begun to be studied. Zemore et al. (2009) analyzed three waves of U.S. National Alcohol Surveys (1995-2005) for lifetime alcohol treatment utilization and perceived treatment barriers in a sample of 4,204 Latinos (52\% women). Higher utilization generally and AA use specifically was found among men as compared to women, and among English-speaking versus Spanish-speaking interviewees. Whereas women and men differed little on perceived barriers, there were greater barriers among Spanish versus English interviewees. Latina women's underutilization of alcohol treatment requires further research but may be partially explained by stigma. Women endorsed fewer barriers to seeking treatment than men, despite the fact that they used less services generally and AA specifically than men. These results may indicate that there 
are more barriers to Latina women's use of treatment and/or stigma resulting from gender and race minority group status that makes it harder for them to do so than for Latino men. If these women are also more likely to be non-English speakers than men, this may also explain part of their lower usage, but that was not reported in this study.

Women-only studies. Kammer (2002) studied predictors of involvement in AA and Narcotics Anonymous (NA) among 164 Black and Hispanic women recruited from hospital detoxification units over the course of one month. More social contacts in 12-step programs and greater motivation were related to attending more meetings. Also, Black women were more likely than Hispanic women to attend 12-step meetings as were women using alcohol (versus alcohol and drugs), women with prior 12-step attendance, and women with greater perceived need for treatment. Black women preferred AA to NA compared with Hispanic women. This study is unique in addressing both AA and NA and comparing Black and Hispanic women, subgroups of women substance abusers in need of study. Still, it is difficult to know if these basic descriptive race group comparisons reflect actual race differences or other associated factors like background characteristics, attitudes toward help seeking, cultural influences, and/or systemic barriers faced by these race groups not examined here. This study suggests that it's important to look at the intersection of race and gender, because women's experiences are not homogeneous and may differ by race. Within-gender race differences may also impact tests of gender differences making it important to look at race when studying gender differences,

particularly since we know that women generally drink less and have less alcohol problems than men and Blacks drink less and have fewer problems than Whites.

\section{Sexual Orientation/Transgender Sexuality}

Three small cross-sectional studies have looked at sexual orientation in relation to AA. 
First, Bradley (2005) conducted focus groups with 29 women from women-only AA groups and found that, compared to heterosexual women, lesbian women were more critical of sexism and heterosexism in language of AA program literature and male God images. However, all women acknowledged the value of the program for women and valued participation in women's meetings. Hall (1994ab, 1996) studied 35 lesbians recovering from alcohol problems, 74\% of whom were actively involved in AA. Few attended lesbian-only AA meetings and most associated with mainstream AA. Participants reported experiencing various tensions in AA and also with the fact that their treatment providers viewed AA as a necessary part of treatment. Participants identified beliefs about AA as one source of conceptual disagreement with their providers, with half of participants feeling invisible or unwelcome in AA and most providers seeing AA as an essential part of treatment. Some continued in AA as peripheral members, but $26 \%$ eventually avoided AA. AA was also an issue raised when discussing providers who tried to push them to attend AA.

Lombardi (2007) studied 90 participants identified as transgender or transsexual. Participants experienced more transphobic events from alcohol/drug treatment program staff than with other clients or within self-help programs. For the most part, participants felt that programs did not address trans issues and they had problems with self-help group members including, from most to least common, receiving little support, not being allowed to talk about trans issues, verbal abuse, being pressured for sex, physical abuse, and being required to wear biological-sex appropriate clothing. Experiencing transphobic events from other group members was associated with having a current problem with drugs or alcohol.

In summary, more work is needed as only a few small studies have examined sexual orientation/identity in relation to AA. Current studies suggest problems for sexual minorities of 
feeling marginalized by sexism, homophobia, and transphobia, all of which may lead to less perceived support and even dropping out of the program. These findings suggest that some subgroups of women may be less able to access effective support from AA and other mutual aid groups, which may contribute to less overall efficacy of such programs for women than men.

\section{Interpersonal/Relational Factors}

Several interpersonal/relational factors, including perceived control, coping, and social support, may moderate the effects of gender on AA and other mutual aid group's utilization and impacts. AA makes clear that sobriety is dependent on working the program with help of others, not alone, so social support, including asking for help and being helped are also important. Part of doing this may be giving up control and reliance on self-will, which can enable one to ask for help and rely on guidance of others. In an attempt to understand differences in control beliefs and relational patterns of women as a function of AA attendance, Sandoz (1995) studied 52 individuals in AA recovery (33\% women) and 27 normal drinking women and found that, compared to normal drinking women, women in recovery had more external locus of control regarding drinking, less spousal dependency, and less intimacy with parents. Bivariate comparisons showed no gender differences in internal-external and drinking-related locus-ofcontrol scales; although women in recovery were less dependent on their spouses than were men. This suggests that women in recovery may have higher levels of functioning and perhaps have become more independent from significant others. Further research is needed to know if it is AA's impact on these factors leading to such differences or if women entering recovery are simply different on these factors from the comparison groups, and perhaps from alcoholic women not entering recovery, a group not studied here. These findings may suggest that men and women in recovery learn to adopt more nontraditional sex role behaviors (e.g., men learn to 
express emotions/ask for help and women learn to become more independent and take care of themselves). Both women and men in AA (either alone or in addition to treatment) have been shown to have more interpersonal problems compared to problem drinkers who did not seek help (Tucker \& Gladsjo, 1993), which does not support the notion that different patterns of interpersonal dysfunction drive gender differences in help seeking. Zemore (2004) examined how helping activities affect sobriety in 198 individuals recruited at AA meetings, Women for Sobriety meetings, treatment programs, and through personal connections (40\% women). Compared to men, women reported less AA involvement, helping others in the context of their recovery (e.g., AA), and helping in the community. This may have been due to sampling procedures, however, because fewer women than men were recruited from AA, and recruitment from AA was related to more AA involvement and recovery-related helping. In Zemore and Kaskutas' (2008) sample of participants in chemical dependency treatment $(\mathrm{n}=503)$ and residential programs $(n=230)(33 \%$ women overall $)$, even though women had higher levels of peer helping (e.g., similar others offering emotional, information, or tangible aid) compared to men, 12-step involvement and peer helping predicted greater likelihood of sobriety over time for both genders, with helping showing an indirect effect on sobriety via 12-step involvement.

Studies do show men and women differ in coping but future research is needed to determine whether coping and gender interact to influence AA variables. Humphreys et al. (1994) showed that, among problem drinkers, women used more active cognitive coping strategies and received more support from friends and extended family than men in dealing with stress. Unfortunately, Humphreys and colleagues did not test whether gender interacted with AA affiliation to affect these psychosocial variables. Similarly, Timko et al. (2005) found differences in coping, stress, and support for women and men with alcohol use disorders but did not report 
whether these psychosocial factors had different effects on drinking outcomes according to AA participation for women and men, a possibility that should be examined in future research. Such analyses could show whether AA affiliation has different effects on coping and support and subsequent drinking outcomes of women and men over time.

Qualitative studies might be particularly useful for determining whether different interpersonal factors impact recovery differently for women and men. For example, Aaltonen and Makela's (1994) comparison of 100 stories in a Finnish AA empirical journal (50\% written by women) revealed that women were more likely to focus on the present and experiences in AA, social relationships, positive emotions, and negative emotions triggered by shame and guilt. Men, in contrast, were more likely to focus on the past and trying to understand their lives in causal terms, social deviance, and negative emotions triggered by inferiority. Thus, the themes relevant to recovery might differ by gender. If so, treatment and intervention approaches could be tailored differently to men and women to address these different themes. These results suggest that different emotions may need to be targeted by treatment programs or reduced by mutual aid groups for men and women. For example, shame and guilt may be more central for women while inferiority may predominate for men, so perhaps single-gender mutual aid groups should focus on reducing distinct negative emotions most salient for each gender. Researchers should test whether gender differences in AA outcomes are mediated by reductions in different emotions for men and women. These studies suggest that women appear to benefit more from social support and sponsor relationships in AA in comparison with men. Studies of women only might offer insight into why this is the case.

Women-only studies. Rush's (2002) study of women showed that reciprocal support was the strongest predictor of group social support. Women with sponsors scored higher than those 
without sponsors on total social support. Availability of support was the strongest contributor to both personal and overall perceived social support. Rush concluded that availability of support and sponsorship are important parts of a supportive environment for women in sobriety. While this may be true for both men and women seeking sobriety, there may be gender differences in the role of support and sponsorship, which should be studied.

Other results suggest the importance of AA sponsors in particular. For example, Huselid et al. (1991) studied 30 women in a halfway house for chemical dependency problems who received daily individual and group counseling and attended AA meetings (because $87 \%$ of women abused alcohol in addition to drugs). Program completion was not significant related to the amount or helpfulness of social support received from family, friends, spouse, church groups or clergy; AA in general; nor the halfway-house counselors, staff, and peers. However, women who perceived that they received a considerable amount of helpful support from an AA sponsor spent more time in the program and were more likely to complete the program successfully. Clearly AA sponsor support may be critical to treatment and recovery of women, and this may differ for men, who may have more difficulty admitting they need help and seeking support from a sponsor. While some research shows that having a sponsor is related to later abstinence controlling for gender, studies have not examined whether the sponsor-abstinence association varies by gender (Kingree \& Thompson, 2011). Freeman's (2001) study of 60 women alcoholics who were new affiliates to AA showed that attachment styles, social support, and prior therapy did not predict continuous days of abstinence over 3 months, but these factors may be important in influencing timing of affiliation, commitment, and outcomes of AA, so need further study.

\section{Spirituality}

Several studies have examined spirituality in relation to AA attendance and outcomes. 
This is important because AA is a spiritual program at its core, and spiritual development might be a crucial aspect of the program and how it facilitates sobriety. Belief in a higher power or God and development of a relationship with that higher power is thought to be one important source of strength that alcoholics get from AA that aids sobriety. Studies of spirituality appear to consider this construct a possible mediator of AA recovery outcomes, but it may also be an outcome and/or moderator of AA's effects and may operate differently for men and women.

Some studies suggest differences in spiritual orientation could produce gender differences in AA experiences. For example, Glickman et al. (2004) studied gender differences in clients in a 12-step program adapted for methadone treatment program clients and compared those attending the program ( $n=26,58 \%$ women) to a matched sample of those who did not $(n=26,35 \%$ women). Women reported more spiritual orientation than men among participants in the 12-step program, but not in the comparison group. More 12-step women attended religious services or spiritual meetings than 12 step men. In Aaltonen \& Makela’s (1994) study, women and men writers in the Finnish AA journal used the phrase "higher power" equally, but women referred to "God" more than did men.

Poage et al. (2004) surveyed 53 recovering alcoholics volunteers from AA groups (34\% women) to examine links of spirituality, contentment (e.g., personal contentment with one's life and surroundings), and stress. Spirituality related to greater contentment for both women and men, but to less stress for women only. Further, greater spirituality, but not contentment or stress, related to longer sobriety. Murray et al. (2003) studied 144 AA participants (38\% women) and the importance of spirituality was positively and significantly correlated with perceptions that God or a related higher power has control over one's drinking behavior for women but not men. In contrast, spiritual practice (e.g., praying, going to AA meetings) was significantly and 
positively correlated with beliefs about God's/related Higher Power's control for men but not women. This may suggest that certain practices impact men's sobriety by reinforcing their belief in a Higher Power, while this pathway is not evident for women. Tonigan et al. (2002) studied Project MATCH outpatient $(n=952)$ and aftercare $(n=774)$ samples longitudinally and found that AA attendance related to reduced drinking intensity and increased abstinence regardless of belief in God for men and women, and no relation was found between gender and expressed God belief. Robinson et al. (2007) collected longitudinal survey data on 123 outpatients adults with alcohol use disorders (34\% women) and found increases in daily spiritual experiences and sense of purpose or meaning in life were related to absence of heavy drinking at 6 months, regardless of gender or AA involvement. Bodin's (2006) study of adults entering treatment showed that women were more likely than men to have experienced a spiritual awakening (i.e., epiphany) through AA, although this study did not test spirituality as a moderator of AA's effects. Oakes et al. (2000) studied 78 AA participants (47\% women) to examine the effects of problem solving as well as spiritual support, spiritual openness, and religious faith practice on long-term sobriety. AA involvement, spiritual openness, and religious practice each predicted longer sobriety for men but not women. Also, purpose in life, another spiritual factor, was related to drinking status and length of sobriety for men but not for women. Changes in beliefs and spirituality that occur in recovery appear to be important for reducing drinking and maintaining sobriety (Robinson et al., 2007; 2011).

\section{Women-only studies.}

Rush (2000) studied how spirituality predicted active participation in AA for at least 1 year in a sample of 125 sober alcoholic women. The number of AA meetings attended weekly contributed to both empowerment and spirituality. Although spirituality might affect how much one 
embraces the AA philosophy and engages in the program, participating in AA might also increase spirituality, given that this is a major focus of the program. Length of sobriety was not correlated with any of the major variables (e.g., empowerment, spirituality).

Existing studies are small and exploratory in nature, these two constructs are often interrelated, and studies have not formally tested the mediating effects of these constructs on the effect of AA on outcomes.

\section{Mental Health and Mental Illness}

Several studies have examined mentally ill populations and/or how mental health problems relate to affiliation and outcomes of AA. Pristach and Smith (1999) studied 60 psychiatric inpatients with alcohol use disorders (35\% women) and found no significant differences in prior AA attendance by gender. Regular past attendance at AA was significantly associated with a positive attitude toward AA for men, but not for women. In Rychtarik et al.'s (2000) sample of 277 AA members (38\% women), there were no gender differences in attitudes toward taking medication to reduce risk of relapse. In Kelly et al.’s (2010) study of Project MATCH data, alcohol dependent adults received treatment $(N=774,20 \%$ women in aftercare; $N$ $=952,27 \%$ women in outpatient) as part of a clinical trial and were assessed 5 times over 15 months. AA attendance related to less depression, but not less anger over time. No support was found for anger as a mediator of AA attendance on drinking outcomes, but depression did mediate AA's positive effect on drinking outcomes. Women had more depression than men but there were no gender differences in effects of AA on anger, depression, or overall on drinking outcomes. Gomes and Hart's (2009) study of alcoholic inpatients of a program based on the 12 steps of AA found no gender differences in depressive or anxiety symptoms at a 2-year followup. Laudet et al. (2003) interviewed 263 individuals (27\% women) seeking help at meetings of 
Double Trouble in Recovery, a mutual aid program adapted from the 12-step model to address needs of dually diagnosed persons. Gender did not predict whether participants stayed in the program at a 1-year follow-up. In another study of DTR, Magura et al. (2007) found that, in 310 interviewees ( $28 \%$ women), men had better self-efficacy for recovery and quality of life than did women. Morgenstern, Kahler, and Epstein (1998) examined whether Type B substance abusers (e.g., a severe subgroup of substance abusers with more personality risk factors of impulsivity, sociopathic, sensation-seeking, tense, hostility, more drug use, and more psychiatric problems than other substance abusers) would have more trouble than Type A's (a less severe group) engaging in the 12-step treatment process in a longitudinal study. Regardless of whether participants were classified as Type B or Type A, gender did not affect their vulnerability, substance abuse or psychiatric symptoms, or treatment process/outcome. Bogenschutz and Akin (2000) studied 81 dual diagnosis outpatients (37\% women) regarding attendance and attitudes towards 12-step meetings and found men and women had similar high levels of participation in 12-step groups. Men had higher scores on positive beliefs about the 12 steps, whereas women were higher in lifetime (but not past 90-day or 1-year) meeting attendance. Tomasson and Vaglum (1998) studied aftercare sought by 341 patients discharged from inpatient alcohol and substance abuse treatment ( $30 \%$ women). Correlates of AA attendance varied by gender. For men, being schizophrenic related to less odds of AA attendance, whereas being younger and having more weeks of work before index admissions predicted greater AA attendance. For women, only younger age predicted higher AA attendance. Having more psychiatric diagnoses was related to more professional aftercare during the follow-up period, controlling for age and polysubstance use for women, but not for men, but number of diagnoses was not related to AA attendance for men or women. These results suggest mental health diagnoses may relate to AA 
attendance differently by gender, but do not tell us whether the impact of gender on AA varies according to mental health status.

Thevos et al. (2000) compared 397 matched female alcoholics with social phobia to a sample of 297 female alcoholics without social phobia and found that women with social phobia showed delayed relapse to drinking when treated with cognitive behavioral therapy rather than 12-step facilitation, whereas the reverse was true for women without social phobia. These data suggest that cognitive behavioral therapy is superior to 12-step facilitation for the treatment of alcohol problems in socially phobic women seeking outpatient treatment. In Terra et al.'s (2006) sample of 300 alcohol-dependent hospital patients ( $8.3 \%$ female), there were no differences in (a) gender between likelihood of having social phobia or (b) groups with and without social phobia in adherence to and outcomes 6 months after standard alcohol treatment and AA group meetings.

Tonigan et al. (2010) compared 133 women alcoholics with social phobia in Project MATCH to 133 non-social phobic female controls assigned to either a 12-step program or cognitive behavioral therapy. No effects were found on frequency of AA attendance or Step 5 completion (i.e., telling one's sponsor one's $4^{\text {th }}$-step moral inventory), an important milestone in the program. However, regardless of treatment condition, socially phobic women went to fewer meetings and were less likely to have a sponsor than were non-social phobic women. This study is important because it shows that even within women there is variability according to mental health status in aspects of AA participation, suggesting that interactions of such factors with gender should be studied further. Given that men and women tend to have different rates and types of mental health problems generally, further work is needed to understand how mental health status impacts outcomes of AA and other treatments in women as compared to men. 


\section{Criminal Justice and Legal Problems}

Three studies have examined criminal justice/legal problems as outcomes in relation to AA. Speigelman (1994) examined AA referrals in 2,877 municipal court drunk driving cases sampled from 1982 to 1989 in four California sites-women made up less than $10 \%$ of cases. Across the four sites, there was no to little significant relation of gender and AA imposition by the court, perhaps because more of men's cases than women's were assigned to AA where private attorneys were involved. Blonigen et al. (2009) examined data from 558 adults with alcohol use disorders (41\% women) who had not received professional treatment for substance use problems at baseline and were followed up after 1 year and 16 years. Longer duration of AA attendance was related to fewer legal problems at Year 1 and this association was moderated by gender, showing that it held for men more than for women. In another study $(N=622,48 \%$ women), Timko, Moos, and Moos (2009) found that AA participation was related to less trouble with police at the 1-year follow-up, especially for men.

In summary, although few in number, studies of AA and criminal justice/legal variables show consistent gender differences. More work is needed to understand psychosocial factors (e.g., coping, social support, self-efficacy), because they are potentially modifiable and may aid understanding of how AA can work to reduce antisocial behavior and improve criminal justice outcomes in men and women.

\section{History of Victimization in Women in AA}

We now examine what is known about histories of victimization in women in AA because victimization is related to problem drinking and alcoholism (Wilsnack et al., 1997; Kilpatrick et al., 1997) and women are more likely to experience sexual abuse and assault than men (Elliott, Mok, \& Briere, 2004; Wiechelt \& Sales, 2001). Also, we know that women with 
victimization histories are much more likely than women without such histories to have comorbidity of substance use disorders (e.g., alcoholism) and mental health problems (e.g., depression, PTSD) (Stewart \& Israeli, 2002), and, as reviewed above, gender and mental health problems might interact to influence AA's effectiveness.

In Ullman and Najdowski's (2010) study of alcohol-related help seeking in women sexual assault survivors who were current problem drinkers, more extensive trauma histories were associated with greater AA meeting attendance. Assault-related avoidance coping was marginally related to greater AA meeting attendance. Greater histories of trauma may lead to AA attendance in women, which may explain the high prevalence of victimization in AA samples. In Lipsky et al.'s (2006) study of 182 women who had experienced intimate partner violence and were referred to a violence intervention and prevention center and 147 controls in a hospitalbased study, victims were 10 times more likely to report alcohol dependence, abuse, use of illicit drugs in the past 12 months, and alcohol program utilization than were non-victims. Smith (1992) found that $30 \%$ of 92 women seeking help from AA or an alcohol treatment unit had experienced violence in the home. Kammer (2002) found that women who attended AA were more likely to have some income from working and histories of sexual assault and physical assault than those attending NA. Sanders (2009) surveyed a nonprobability sample of 167 participants from women-only AA groups and found that $60 \%$ of women had either been physically or sexually abused or assaulted or had some combination of these experiences in their past. This research is consistent with other work showing that many women alcoholics have been physically or sexually abused in the past (Covington, 1982; Langeland \& Hangers, 1998;

Murphy et al. 1980; Wilsnack et al., 1994), and research showing an even higher prevalence of victimization histories in women in substance abuse treatment (Hein, Cohen, \& Campbell, 2005). 
Other exploratory research shows that in addition to histories of abuse common in women with alcoholism and those in treatment (Swett \& Halpert, 1994), AA may not always be a safe place for women.

It's possible that women who have abuse histories might have more mental health problems, which may make it harder for them to engage with 12-step programs, especially given the focus on powerlessness in Step 1, which they have already experienced due to their abuse histories. This is supported by Ferrari et al.'s (1997) study of 65 African-American Oxford House residents (49\% women): Significantly more women than men were sexually abused in adulthood, and women reported significantly less working on 12-step programs than did men. While few studies have examined the role of child sexual abuse, Wiechelt and Sales (2001) found that women in AA have experienced higher rates of child sexual abuse than women not in AA. They also found that shame was related to poorer recovery, including social adjustment problems and higher risk of relapse (Wiechelt \& Sales, 2001), regardless of victimization history. This study was small and lacked adequate power, but suggests that we should look at generalized measures of shame that may be distinct from abuse-related shame in future work. This has not been teased apart, but could help to explain the link between child sexual abuse histories and alcoholism in women (Wilsnack et al., 1997).

Bogart and Pearce (2003) surveyed 55 women about their experiences with " $13^{\text {th }}$ stepping"- a euphemism used by members of AA to refer to people (typically men) who target new, more vulnerable members (typically women) for dates or sex. At least $50 \%$ of participants experienced $13^{\text {th }}$ stepping, and $75 \%$ of those attending women-only AA groups had such experiences during their attendance at mixed-gender groups. Four study participants reported being raped by men in AA. The authors noted that women need to be prepared to protect 
themselves from $13^{\text {th }}$ stepping, particularly women with sexual abuse histories who may be especially vulnerable and should be referred by treatment providers to women-only groups when possible. Finally, one recent study showed no gender differences in perceptions of safety at AA and NA meetings in youth, although more negative incidents were reported in NA than AA (Kelly et al., 2011).

In summary, women with alcohol problems are likely to have victimization histories. Such histories might affect whether women choose to attend AA and how women respond to AA, and might even put women at risk for future victimization inside the program.

\section{Gender-Based Critiques of AA and Data Addressing These Limitations}

Based on results from surveys of AA members, Chappel (1993) has argued that one of the least dramatic but most significant changes in the composition of AA membership is the increase in the number of women members. In 1968, 22\% of AA members were women; by $1989,35 \%$ were women, so raw numbers of women are increasing as well as their proportion in AA as a whole.. Chappel noted that one way of interpreting these data is that AA has moved successfully from its early bias against women. That is, previously many people in our culture did not believe that women could be alcoholics, whereas now that gender roles are more liberal, alcoholism in women is more openly acknowledged and less stigmatized. Thus, women may feel freer to admit they have a drinking problem and seek help for it than in the past. Alternatively, this difference may reflect a greater willingness on the part of women to accept a treatment focused on spiritual experience with growth and development activities, perhaps due to the women's liberation movement and growth of the self-help movement in the 1970s and 1980s. Despite increased acknowledgment of women's alcoholism and willingness to seek help over time, AA has also been criticized for gender biases that may make the program less attractive 
and/or effective for women (Rapping, 1996). It has been argued that some 12-step concepts such as powerlessness and making amends could be difficult for some women alcoholics to accept, particularly because women often have trauma histories and come from a place of being victimized and harmed by others (Covington, 1994; Miller et al., 1987). Also, because of AA's reliance on concepts of God and a Higher Power and the fact that it was developed by a small group of White privileged men, much of the Big Book and practices of the program are biased according to the perspective of men alcoholics. Thus, AA can be viewed as sexist and reinforcing women's subordinate traditional roles (Wilke, 1994). Some have also criticized AA for encouraging women to deal with their problems as personal as opposed to political (Rapping 1996). Because of this, some have tried to construct alternative versions of the 12 steps that may be more helpful and more applicable to women navigating the recovery process, and to validate these alternatives with qualitative data from women alcoholics (Berenson, 1991; Herndon, 2001; Sanders, 2006).

Gomberg (2003) explains that stereotypes and myths still prevail, such as the longstanding belief that women alcoholics have poorer prognoses than men alcoholics. While these myths still exist, it's important to dispel them by examining gender differences in empirical research. For example, Gomberg (2003) notes that women alcoholics generally have more positive family histories of alcoholism, a later onset of drinking and related problems, more marital disruption, and more comorbidity than do men alcoholics. She also points out that an earlier review of treatment outcomes showed few significant gender differences (Vannicelli, 1986). Such data indicate that there are gender differences in some aspects of alcoholism, but not necessarily in treatment efficacy. This review substantiates this claim that extant findings are mixed about gender differences in outcomes of AA. Given that many studies find few gender 
differences, the program may work equally well for women who become involved and committed to working the program. Still, women's experiences of affiliating with AA and their experiences in the program may differ from men's, and the mechanisms of AA's effectiveness may also differ by gender.

We now review a few qualitative studies that have examined how women view the 12 steps as part of their recovery in order to provide some contextual information about women's subjective experiences of the AA program.

Working AA's 12 Steps. Unfortunately, few studies have examined women alcoholics' perceptions of the steps, although there are 4 qualitative studies on this topic. While concerns about gender bias in AA were mentioned earlier, at least two qualitative studies to date show that women alcoholics in AA do not appear to have significant problems due to sexist biases of AA, although many do acknowledge these biases exist (Bradley, 2005; Sanders, 2006; 2009). Sanders (2006) examined how 167 women sampled from women-only AA groups described working the 12 steps. She argues that the feminist analysis that critiques AA as oppressive and patriarchal is not reflected in how these women work the steps and that women adapt and work the steps in ways that work for them despite the male-dominated culture and language of the 12 steps. She finds that some of the steps and themes for women are the same as described in the AA "Big Book" (the core text used in the AA program, which describes the program, its history, stories of AA members, etc.) and similar to how men in the program approach the 12 steps. However, others have distinct meanings and are addressed by women in gender-specific ways to fit their experiences and help them achieve sobriety. She detailed how women in her study conceptualized each step of the program. Sanders asserts that women's recovery in AA is not a threat to feminist empowerment but is in fact a form of women's empowerment. 
In another study examining women's experiences in AA, Bradley (2005) conducted focus groups with 29 participants recruited from women's AA discussion group meetings. Women reported adapting the steps and found them to be useful. Even though some feminist critiques of AA were acknowledged to exist by participants (e.g., sexist language, male God images), women saw the program as helpful and/or adapted it to suit their needs.

Powerlessness and the $\mathbf{1}^{\text {st }}$ Step. A couple of studies address women's experiences of powerlessness and the $1^{\text {st }}$ step. Sanders' (2006) study of 167 women from women-only AA groups argues that the powerlessness over alcohol of the $1^{\text {st }}$ step was difficult for women to face, but provided relief once they did so. Her participants found denial and resistance to giving up one's own willpower the hardest barriers to acknowledging powerlessness.

Bradley (2005) argued that women saw AA as being critical of patriarchal notions of dominance power (e.g., power-over or willfulness) and as promoting affiliation and mutuality (e.g., power-to or willingness), a change in their conceptualization of power that occurred over time. She argues that a focus on self-growth and cooperation in AA is actually more consistent with feminist models of power. Women spoke of AA and their relationship to sponsors that involved nurturing, supporting, and sharing experiences as important and said AA empowered them by helping them become sober and maintain sobriety. Although issues of shame and stigma were common for women, most said the program's focus on spirituality was important and helpful to their recovery, including developing a relationship with a higher power. Accepting surrender and powerlessness helped them develop a sense of empowerment and the steps helped them achieve sobriety and create changes in other areas of their lives, including spiritual transformation and self-acceptance. AA's spiritual principles also taught them values of humility, honesty, trust, and responsibility in daily living, as well as strategies to deal with 
feelings and life situations. Finally, a sense of community was reported during women's meetings and having support of women in recovery was seen as critically important and helped facilitate improved relationships, self-esteem, and attitudes.

Matheson and McCollum (2008) explored experiences of powerlessness by interviewing 13 women with an average of 10 years of recovery, a convenience sample recruited from 12-step programs meetings for substance abuse. Overall, women felt favorably toward powerlessness in the $1^{\text {st }}$ step and that acknowledging powerlessness was very important to their recovery, regardless of the length of time in recovery. Women thought about powerlessness in terms of metaphors associated with babies or young children, who they felt like in terms of feelings of vulnerability, fear, especially related to being early in their recovery process. Feelings of powerlessness were also associated with oppression and negative pressure from society or circumstances outside their control generally. Acknowledging their inability to control these outside forces was in most cases a positive experience of powerlessness that was freeing and came as a relief. Finally, relief was a result of accepting powerlessness in the $1^{\text {st }}$ step, which meant acknowledging lack of power over external forces, but not powerlessness to be an agent of one's own will.

Working the Rest of the 12 Steps. According to Sanders (2006), the language of coming to believe in a male God or Higher Power is acknowledged to be alien to some women, but the fact that it is softened to be God or a "higher power as we understand it" as expressed in Step 2 makes this possible for women to find this as they personally define it. Many women struggled with turning one's self and one's will over to a higher power as an ongoing process in the $3^{\text {rd }}$ step. Sanders argues there is no abject powerlessness or total surrender in the narratives of her participants and that these processes are a struggle, which in itself shows the women have plenty 
of will. Women view the $4^{\text {th }}$ step-developing a fearless and searching moral inventory of oneself — as a task of becoming honest with one's self. Sanders' interviewees expressed that fear is related not to resentment or a self-centered fear as discussed in the Big Book, but more to looking at one's self, due to fear of facing feelings of shame and pain. Accepting responsibility was another difficult barrier to completing the $4^{\text {th }}$ step according to the women. Many women noted listing character assets as well as defects in doing this step. Women noted that Step 5 of telling someone their moral inventory was a relief. The next 2 steps were approached as a set of tools for self-examination where they had to become willing and able to ask God to remove their character defects (Step 6) and actually ask God to remove their defects (Step 7). Related to Step 8 -- making a list of amends to make to others and carrying out those amends (Step 9) was not difficult for women, but making amends or forgiveness of oneself was, as many women blamed themselves and judged themselves harshly. In step 10, continuing to take personal inventory, women were more likely to describe self-pity and temper tantrums than just selfishness, typically mentioned in AA literature written by men. Step 11 or "improving our conscious contact with God/Higher Power and his will for us" was addressed by attending meetings, praying, and reading AA literature frequently, as well as other spirituality practices such as AA workshops. Step 12- service to others - was common for women who served as sponsors and were involved in AA at all levels. Women also made close friendships via being sponsored and sponsoring others.

\section{Conclusions}

There are many limitations of existing research on AA and much more work is needed on gender differences and women's unique experiences in AA and related mutual aid groups.

Despite many years of research on AA, conclusions of some prior reviews still hold and may 
also apply to results of studies addressing gender and AA reviewed here. For example, Kownacki and Shadish's (1999) review indicated that the design and methodology of studies examining effects of AA affiliation have an impact on research results. Quasi-experiments were compromised by severe selection biases and selecting coerced subjects typically biased even randomized studies. Randomized studies revealed worse AA outcomes than did nonrandomized studies. Tonigan, Toscova, and Miller's (1995) meta-analysis of 74 studies examining drinkingrelated outcomes of AA affiliation revealed other issues related to study design. Specifically, Tonigan and colleagues found that (a) AA studies lacked sufficient statistical power to detect relations of interest, (b) effects differed by study sample (e.g., AA participation and drinking outcomes were more strongly related in outpatient than inpatient samples), and (c) better designed studies were more likely to yield positive psychosocial outcomes related to AA attendance. Most recently, Kaskutas (2009) reviewed evidence on AA's efficacy and found strong evidence for 5 out of 6 criteria for establishing causality. She concluded that rates of abstinence are twice as high for those attending AA (e.g., magnitude), greater attendance is related to higher abstinence (e.g., dose-response) these relationships are found for different samples and follow-up periods (e.g., consistency), prior AA attendance predicts later abstinence (e.g., temporality), and mechanisms of action predicted by behavior change theories are present in AA (e.g., plausibility). Given the limited number of experimental trial studies, Kaskutas concludes that evidence for the criteria of specificity of AA's (or 12-step programs') effect is mixed, as two trials showed positive effects of AA, one showed null effects, and one showed negative effects.

Although this evidence is positive for AA overall, these reviews do not speak to gender effects specifically. In particular, studies are needed to examine pathways by which women and 
men come into AA and how differences between women and men who actually enter the program influence their experiences and outcomes. Research is needed testing for such effects with larger subsamples of women to compare them to men, as well as in samples of women separately to be able to test for subgroup differences within women. Researchers need to make data accessible to others who are interested in testing effects of gender. Because so few studies report gender analyses relative to the vast number of studies looking at AA overall, it's quite possible that the "file drawer problem" (e.g., greater likelihood of nonpublication of studies show nonsignificant results) applies and that there might actually be no gender differences.

Despite the limitations in the existing literature on AA and gender, this descriptive review shows that there is some evidence of gender differences in AA affiliation and outcomes. Much more research is needed to fully understand gender differences and women's experiences in AA and other mutual aid groups. Many studies have cross-sectional designs and small samples that contain few women. Most studies comprise persons entering or already in treatment settings, so it is difficult to know how much those experiences may impact drinking outcomes, as opposed to understanding the effects of AA alone. Still, studies tend to find either no gender differences or that women benefit to a greater extent from AA than do men, perhaps due to greater involvement in the program (e.g., greater meeting attendance, support giving and receipt, and contact with sponsors). To date, few studies of women in AA exist and most are small and exploratory in nature. Those studies show that women benefit from AA and other mutual aid programs like Women For Sobriety and that women may adapt AA and its 12 steps in particular to suit their own unique needs. Social support obtained through AA, relationships with sponsors, and women-only AA meetings are all factors that appear to be particularly helpful to women in recovery. Women of diverse ages, races, sexualities, and those with mental health problems, 
criminal justice contacts, and victimization histories all need to be studied further to understand their experiences of AA and how the program impacts their drinking outcomes. Research should also consider the moderating role of other factors which have been shown to relate to alcoholrelated help seeking and outcomes for women, including study region (e.g., Witbrodt \& Romelsjo, 2010; Small et al., 2010), marital status (Kammer, 2002), and education (Ullman \& Najdowski, 2010). In this way, we can better understand how the effects of AA and mutual aid groups vary for different population subgroups, which may also point toward how to best position other substance abuse treatment services in communities. 


\section{References}

Aaltonen, I., \& Makela, K. (1994). Female and male life stories published in the Finnish Alcoholics Anonymous Journal. International Journal of the Addictions, 29, 485-495.

Aase, D., Jason, L., \& Robinson, W. (2008). 12-step participation among dually-diagnosed individuals: A review of individual and contextual factors. Clinical Psychology Review, $28,1245-1248$.

Aharon, S. (2000). Addiction-specific support group use, personality characteristics and recovery status in substance abusers: A follow-up study. Unpublished doctoral dissertation. University of Toronto, Toronto, CN.

Alcoholics Anonymous. (2008). Alcoholics Anonymous Membership Survey 2007. New York: Alcoholics Anonymous World Services, Inc.

Allen, L., Nelson, C., Rouhbakhsh, P., Scifres, S., Greene, R., Kordinak, S., Davis, L., \& Morse, R. (1998). Gender differences in factor structure of the self-administered Alcoholism Screening Test. Journal of Clinical Psychology, 54, 439-445.

Ammon, L., Bond, J., Matzger, H., \& Weisner, C. (2008). Gender differences in the relationship of community services and informal support to seven-year drinking trajectories of alcohol-dependent and problem drinkers. Journal of Studies on Alcohol and Drugs, 69, 140-150.

Beckman, L. J. (1993). Alcoholics Anonymous and gender issues. In B. S. McCrady \& W. R. Miller (Eds.). Research on Alcoholics Anonymous: Opportunities and alternatives. New Brunswick, NJ: Rutgers Center for Alcohol Studies.

Berenson, D. (1991). Powerlessness-liberating or enslaving? Responding to the feminist critique of the twelve steps. In C. Bepko (Ed.). Feminism and addiction (pp. 67-84). New 
York: Haworth Press.

Blonigen, D., Timko, C., Moos, B., \& Moos, R. (2009). Treatment, Alcoholics Anonymous, and 16-year changes in impulsivity and legal problems among men and women with alcohol use disorders. Journal of Studies on Alcohol and Drugs, 70, 714-725.

Bodin, M. (2006). Gender aspects of affiliation with Alcoholics Anonymous after treatment. Contemporary Drug Problems, 33, 123-141.

Bogart, C.J., \& Pearce, C.E. (2003). “13 ${ }^{\text {th }}$-Stepping”: Why Alcoholics Anonymous is not always a safe place for women. Journal of Addictions Nursing, 14, 43-47.

Bogenschutz, M., Geppert, C., \& George, J. (2006). The role of twelve-step approaches in dual diagnosis treatment and recovery. American Journal of Addictions, 15, 50-60.

Bogenschutz, M. P., \& Akin, S. J. (2000). 12-Step participation and attitudes toward 12-Step meetings in dual diagnosis patients. Alcoholism Treatment Quarterly, 18, 31-45.

Booth \& McLaughlin (2000). Barriers to and need for alcohol services for women in rural populations. Alcoholism: Clinical and Experimental Research, 24, 1267-1275.

Bradley, C. A. (2005). An exploration of women's experience in Alcoholics Anonymous. Unpublished doctoral dissertation, Fordham University, New York, NY.

Brown, T., Seraganian, P., Tremblay, J., \& Annis, H. (2002). Matching substance abuse aftercare treatments to client characteristics. Addictive Behaviors, 27, 585-604.

Chappel, J. (1993). Long-term recovery from alcoholism. Psychiatric Clinics of North America, $16,177-187$.

Chi, F., Kaskutas, L., Sterling, S., Campbell, C., \& Weisner, C. (2009). Twelve-Step affiliation and 3-year substance use outcomes among adolescents: social support and religious service attendance as potential mediators. Addiction, 104, 927-939. 
Connors, G., \& Dermen. K. (1996). Characteristics of participants in Secular Organizations for Sobriety (SOS). American Journal of Drug and Alcohol Abuse, 22, 281-295.

Connors, G., Maisto, S., \& Zywiak, W. (1998). Male and female alcoholics’ attributions regarding the onset and termination of relapses and the maintenance of abstinence. Journal of Substance Abuse, 10, 27-42.

Copeland, J., Hall, W., Didcott, P., \& Biggs, V. (1993). A comparison of a specialist women's alcohol and other drug treatment service with two traditional mixed-sex services: Client characteristics and treatment outcome. Drug and Alcohol Dependence, 32, 81-92.

Covington, S. (1994). A Woman's way through the twelve steps. Center City, MH: Hazelden.

Davis, M. \& Jason, L. (2005). Sex differences in social support and self-efficacy within a recovery community. American Journal of Community Psychology, 36, 259-274.

DelBoca, F., \& Mattson, M. (2002). The gender matching hypothesis. In R. Longabaugh \& P. Wirtz (Eds.), Project MATCH hypotheses: Results and causal chain analyses. Project MATCH Monograph Series, Vol 8, NIAAA, Bethesda, MD: 223-238.

DeLucchi, K. L., \& Kaskutas, L. A. (2010). Following problem drinkers over eleven years: Understanding changes in alcohol consumption. Journal of Studies on Alcohol and Drugs, 71, 831-836.

Elliott, D., Mok, D., \& Briere, J. (2004). Adult sexual assault: prevalence, symptomatology, and sex differences in the general population. Journal of Traumatic Stress, 17, 203-211.

Ferrari, J., Jason, L., Nelson, R., Curtin-Davis, P. (1999). An exploratory analysis of women and men within a self-help, Communal-living recovery setting: A new beginning in a new house. American Journal of Drug and Alcohol Abuse, 25, 305-317.

Finney, J., \& Moos, R. (1995). Entering treatment for alcohol abuse: A stress and coping model. 
Addiction, 90, 1223-1240.

Freeman, M. L. (2001). Attachment, social support, professional therapy, and short-term abstinence in women of Alcoholics Anonymous. Unpublished doctoral dissertation. Alliant International University, San Diego, CA.

George, A., \& Tucker, J. (1996). Help-seeking for alcohol-related problems: Social contexts surrounding entry into alcoholism treatment or Alcoholics Anonymous. Journal of Studies on Alcohol, 57, 449-457.

Gomberg, E. S. (1974). Women and alcoholism. In Franks, V., and Burtle, V. (Eds). Women in Therapy. New York: Brunner-Mazel, Inc., pp. 169-190.

Gomberg, E. (2003). Treatment for alcohol-related problems: Special populations: research opportunities. Recent Developments in Alcoholism, 16, 315-333.

Gomes, K. \& Hart, K. E. (2009). Adherence to recovery practices prescribed by Alcoholics Anonymous: Benefits to sustained abstinence and subjective quality of life. Alcoholism Treatment Quarterly, 27, 223-235.

Greenfield, S., Brooks, A., Gordon, S., Green, C., Kropp, F., McHugh, K., et al. (2007). Substance abuse treatment entry, retention, and outcome in women: A review of the literature. Drug and Alcohol Dependence, 86, 1-21.

Groh, D., Jason, L., \& Keys, C. (2008). Social network variables in Alcoholics Anonymous: A literature review. Clinical Psychology Review, 28, 430-450.

Hall, J. (1994a). The experiences of lesbians in Alcoholics Anonymous. Western Journal of Nursing Research, 16, 556-576.

Hall, J. (1994b). Lesbians recovering from alcohol problems: An ethnographic study of healthcare experiences. Nursing Research, 43, 238-244. 
Hall, J. (1996). Lesbians' participation in Alcoholics Anonymous: Experiences of social, personal, and political tensions. Contemporary Drug Problems, 23, 113-138.

Harris, J., Best, D., Gossop, M., Marshall, J., Lan-Ho, M., Manning, V., et al. (2003). Prior Alcoholics Anonymous (AA) affiliation and the acceptability of the twelve steps to patients entering UK statutory addiction treatment. Journal of Studies on Alcohol, 64, 257-261.

Hasin, D., \& Grant, D. (1995). AA and other help seeking for alcohol problems: Former drinkers in the U.S. general population. Journal of Substance Abuse, 7, 281-292.

Hein, D., Cohen, L., \& Campbell, A. (2005). Is traumatic stress a vulnerability factor for women with substance use disorders? Clinical Psychology Review, 25, 813-823.

Herndon, S. (2001). The paradox of powerlessness: Gender, sex, and power in 12-step groups. Women and Language, 24, 7-12.

Hillhouse, M., \& Fiorentine, F. (2001). 12-step program participation effectiveness: Do gender and ethnic differences exist? Journal of Drug Issues, 31, 767-780.

Hohman, M., \& LeCroy, C. (1996). Predictors of adolescent AA affiliation. Adolescence, 31, 339-352.

Horstmann, M. J. \& Tonigan, J. S. (2000). Faith development in Alcoholics Anonymous (AA). Alcoholism Treatment Quarterly, 18, 75 - 84.

Humphreys, K., Mavis, B., \& Stoffelmayr, D. (1994). Are 12-step programs appropriate for disenfranchised groups? Evidence from a study of post-treatment mutual help involvement. Prevention in Human Services, 11, 165-179.

Humphreys, K., \& Rappaport, J. (1994). Researching self-help/mutual aid groups and organizations: many roads, one journey. Applied and Preventive Psychology, 3, 217-231. 
Humphreys, Phibbs, C., \& Moos, R. (1996). Assessing self-selection effects in evaluations of mutual help groups and professional mental health services: An introduction to two-stage sample selection models. Evaluation and Program Planning, 19, 301-308.

Humphreys, K., \& Klaw, E. (2001). Can targeting nondependent problem drinkers and providing internet-based services expand access to assistance for alcohol problems? A study of the moderation management self-help/mutual aid organization. Journal of Studies on Alcohol, 62, 528-532.

Huselid, R., Self, E., \& Gutierres, S. (1991). Predictors of successful completion of a halfwayhouse program for chemically-dependent women. American Journal of Drug and Alcohol Abuse, 17, 89-101.

Kammer, R. (2002). Predictors of Black and Hispanic women's involvement in Alcoholics Anonymous and Narcotics Anonymous. Unpublished doctoral dissertation. Columbia University, New York, NY.

Kaskutas, L. A. (1994). What do women get out of self-help? Their reasons for attending Women for Sobriety and Alcoholics Anonymous. Journal of Substance Abuse Treatment, $11,185-195$.

Kaskutas, L. A. (1996). Pathways to self-help among women for sobriety. American Journal of Drug and Alcohol Abuse, 22, 259-280.

Kaskutas, L. A. (2009). Alcoholics Anonymous effectiveness: Faith meets science. Journal of Addictive Diseases, 28, 145-157.

Kaskutas, L. A., Weisner, L., \& Caetano, R. (1997). Predictors of help seeking among a longitudinal sample of the general public, 1984-1992. Journal of Studies on Alcohol, 58, $155-161$ 
Kaskutas, L., Weisner, Lee, \& Humphreys (1999). Alcoholics Anonymous affiliation at treatment intake among White and Black Americans. Journal of Studies on Alcohol, 60, 810-816.

Kelly, J. (2003). Self-help for substance use disorders: History, effectiveness, knowledge gaps, and research opportunities. Clinical Psychology Review, 23, 639-663.

Kelly, J., Dow, S., Yeterian, J., \& Myers, M. (2011). How safe are adolescents at AA and NA meetings? A prospective investigation with outpatient youth. Journal of Substance Abuse Treatment, 40, 419-425.

Kelly, J., Magill, M., \& Stout, R. (2009). How do people recover from alcohol dependence? A systematic review of the research on mechanisms of behavior change in Alcoholics Anonymous. Addiction Research and Theory, 17, 236-259.

Kelly, J. F., Myers, M. G., and Brown, S. A. (2000). A multivariate process model of adolescent 12-Step attendance and substance use outcome following inpatient treatment. Psychology of Addictive Behaviors, 14, 376-389.

Kelly, J., Myers, M., \& Rodolico, J. (2008). What do adolescents think about 12-Step groups? perceptions and experiences of two AA-exposed clinical samples. Substance Abuse, 29, $53-62$.

Kelly, J., Stout, R., Magill, M., Tonigan, S., \& Pagano, M. (2010). Mechanisms of behavior change in Alcoholics Anonymous: Does Alcoholics Anonymous lead to better alcohol use outcomes by reducing depressive symptoms? Addiction, 105, 626-636.

Kelly, J., Stout, R., Tonigan, S., Magill, M., \& Pagano, M. (2010). Negative affect, relapse, and Alcoholics Anonymous (AA): Does AA work by reducing anger? Journal of Studies on Alcohol and Drugs, 71, 434-444. 
Kelly, J., Stout, R., Zywiak, W., \& Schneider, R. (2006). A 3-year study of addiction mutualhelp group participation following intensive outpatient treatment. Alcoholism: Clinical and Experimental Research, 30, 1381-1392.

Kertesz, S., Larson, M., Cheng, D., Tucker, J., Winter, M., Mullins, A., Saitz, R., \& Samet, J. (2006). Need and non-need factors associated with addiction treatment utilization in a cohort of homeless and housed urban poor. Medical Care, 44, 225-233.

Keyes, K., \& Hasin, D. (2008). Evidence for a closing gender gap in substance use, abuse, and dependence in the United States population. Drug and Alcohol Dependence, 93, 21-29.

Kilpatrick, D. G., Acierno, R., Resnick, H. S., Saunders, B. E., \& Best, C. L. (1997). A 2-year longitudinal analysis of the relationships between violent assault and substance use in women. Journal of Consulting and Clinical Psychology, 65, 834-847.

Kingree, J.B., \& Thompson, M. (2011). Participation in alcoholics anonymous and posttreatment abstinence from alcohol and other drugs. Addictive Behaviors, 36, 882-885.

Klaw, E., Huebsch, P., \& Humphreys, K. (2000). Communication patterns in an on-line mutual help group for problem drinkers. Journal of Community Psychology, 28, 535-546.

Klaw, E., Luft, S., \& Humphreys, K. (2003). Characteristics and motives of problem drinkers seeking help from moderation management self-help groups. Cognitive and Behavioral Practice, 10, 384-389.

Kownacki, R., \& Shadish, W. (1999). Does Alcoholics Anonymous work: The results from a meta-analysis of controlled outcome studies. Substance Use and Misuse, 34, 1897-1916.

Langeland, W., \& Hangers, C. (1998). Child sexual and physical abuse and alcoholism. Journal of Studies on Alcohol, 59, 336-350.

Laudet, A. B. (2006). The role of social supports, spirituality, religiousness, life meaning and 
affiliation with 12-step fellowships in quality of life satisfaction among individuals in recovery from alcohol and drug problems. Alcoholism Treatment Quarterly, 24, 33-73.

Laudet, A., Magura, S., Cleland, C., Vogel, J., \& Knight, E. (2003). Addictions services: predictors of retention in dual-focus self-help groups. Community Mental Health Journal, 39, 281-297.

Lipsky, S., Caetano, R., Field, C., \& Larkin, G. (2006). The role of intimate partner violence, race, and ethnicity in help-seeking behaviors. Ethnicity and Health, 11, 81-100.

Lombardi, (2007). Substance use treatment experiences of transgender/transsexual men and women. Joumal of LGBT Health Research, 3, 37-47.

Magura, S., Cleland, C., Vogel, H., Knight, E., \& Laudet, A. (2007). Effects of “dual focus” mutual aid on self-efficacy for recovery and quality of life. Administration and Policy in Mental Health and Mental Health ServicesResearch, 34, 1-12.

Mann, R., Smart, R., Zalcman, R., Rush, B., \& Suurvali, H. (2005). Cirrhosis mortality in Ontario: Effects of alcohol consumption and Alcoholics Anonymous participation. Addiction, 100, 1669-1679.

Mann, R., Zalcman, R., Smart, R., Rush, B., \& Suurvali, H. (2006). Alcohol consumption, Alcoholics Anonymous membership, and suicide mortality rates, Ontario, 1968-1991. Journal of Studies on Alcohol, 67, 445-453.

Masudomi, I., Isse, K., Uchiyama, M., Watanabe, H. (2004). Self-help groups reduce mortality risk: A 5-year follow-up study of alcoholics in the Tokyo metropolitan area. Psychiatry and Clinical Neurosciences, 58, 551-557.

Matheson, J. L., \& Mccollum, E. E. (2008). Using metaphors to explore the experiences of 
powerlessness among women in 12-Step recovery. Substance Use and Misuse, 43, 10271044.

McCrady, B., \& Tonigan, S. (2009). Recent research into 12-step programs. In Ries, R., Miller, S., Fiellin, D., \& Saitz, R. (Eds.). Principles of Addiction Medicine, $4^{\text {th }}$ Edition. (pp. 923937). Wolters Kluwer/Lippincott Williams \& Wilkens.

McKellar, J., Ilgen, M., Moos, B., \& Moos, R. (2008). Predictors of changes in alcohol-related self-efficacy over 16 years. Journal of Substance Abuse Treatment, 35, 148-155.

Miller, B A., Downs, W R., Gondoli, D M., \& Keil, A. (1987). The role of childhood sexual abuse in the development of alcoholism in women. Violence and Victims, 2, 157-72.

Moos, R. (2007). Theory-based processes that promote remission in substance use disorders. Clinical Psychology Review, 27, 537-551.

Moos, R., \& Moos, B. (2003). Risk factors for nonremission among initially untreated individuals with alcohol use disorders. Journal of Studies on Alcohol, 64, 555-563.

Moos, R., \& Moos, B. (2004a). The interplay between help-seeking and alcohol-related outcomes: Divergent processes for professional treatment and self-help groups. Drug and Alcohol Dependence, 75, 155-164.

Moos, R., \& Moos, B. (2004b). Long-term influence of duration and frequency of participation in Alcoholics Anonymous on individuals with alcohol use disorders. Journal of Consulting and Clinical Psychology, 72, 81-90.

Moos, R. H., Moos, B. S., \& Timko, C. (2006). Gender, treatment and self-help in remission from alcohol use disorders. Clinical Medicine and Research, 4, 163-174

Moos, R. H., Schutte, K., Brennan, P., \& Moos, B. S. (2004). Ten-year patterns of alcohol consumption and drinking problems among older women and men. Addiction, 99, 829 
$-838$.

Morgenstern, J., Kahler, C., \& Epstein, E. (1998). Do treatment process factors mediate the relationship between Type A-Type B and outcome in 12-step oriented substance abuse treatment? Addiction, 93, 1765-1776.

Murray, T., Malcarne, V., \& Goggin, K. (2003). Alcohol-related God/higher power control beliefs, locus of control, and recovery within the Alcoholics Anonymous paradigm. Alcoholism Treatment Quarterly, 21, 23-39.

Nolen-Hoeksema, S. (2004). Gender differences in risk factors and consequences for alcohol use and problems. Clinical Psychology Review, 24, 98-1010.

Nolen-Hoeksema, S., \& Hilt, L. (2006). Possible contributors to gender differences in alcohol use and problems. Journal of General Psychology, 133, 357-374.

Oakes, K., Allen, J., \& Ciarrochi, J. (2000). Spirituality, religious problem-solving, and sobriety in Alcoholics Anonymous. Alcoholism Treatment Quarterly, 18, 37-50.

Ogborne, A., \& Dewit, D. (1999). Lifetime use of professional and community resources for help with drinking: Results from a Canadian population survey. Journal of Studies on Alcohol, $60,867-872$

Plant, M. (2008). The role of alcohol in women's lives: A review of issues and responses. Journal of Substance Use, 13, 155-191.

Poage, E., Ketzenberger, K., \& Olson, J. (2004). Spirituality, contentment, and stress in recovering alcoholics. Addictive Behaviors, 29, 1857-1862.

Pristach, C., \& Smith, C. (1999). Attitudes towards Alcoholics Anonymous by dually-diagnosed psychiatric inpatients. Journal of Addictive Diseases, 18, 69-77.

Project MATCH Research Group (1997). Matching alcoholism treatments to client 
heterogeneity: Project MATCH posttreatment drinking outcomes. Journal of Studies on Alcohol, 58, 7-29.

Raimo, E., Daeppen, J., Smith, T., Danko, G., \& Schuckit, M. (1999). Clinical characteristics of alcohol-dependent subjects history of alcohol of alcoholism in with and without a treatment. Alcoholism: Clinical and Experimental Research, 23, 1605-1613.

Rapping, E. (1996). The Culture of Recovery: Making Sense of the Self-Help Culture. Boston: Beacon Press.

Reigle, C., \& Dowd, T. (2004). Predicting affiliation with Alcoholics Anonymous, Health Education Journal, 63, 81-88.

Riper, H., Kramer, J., Keuken, M., Smit, F., Schippers, G., \& Cuijpers, P. (2008). Predicting successful treatment outcome of web-based self-help for problem drinkers: Secondary analysis from a randomized controlled trial. Journal of Medical Internet Research, 10 (4), e46, URL: http://www.jmir.org/2008/4/e46/.

Robinson, E., Cranford, J., Webb, J., \& Brower, K. (2007). Six-month changes in spirituality, religiousness, and heavy drinking in a treatment-seeking sample. Journal of Studies on Alcohol and Drugs. 68, 282-290.

Robinson, E., Krentzman, A., Webb, J., \& Brower, K. (2011). Six-month changes in spirituality and religiousness in alcoholics predict drinking outcomes at nine months. Journal of Studies on Alcohol and Drugs, 72, 660-668.

Roman, P.M. (1988). Treatment issues. In: Women and Alcohol Use: A Review of the Research Literature. National Institute on Alcohol Abuse and Alcoholism. DHHS Pub. No. (ADM) 88-1574. Washington, DC: Supt. of Docs., U.S. Govt. Print. Off., pp. 38-45.

Room, R., \& Greenfield, T. (1993). Alcoholics anonymous, other 12-step movements and 
psychotherapy in the US population, 1990. Addiction, 88, 555-562.

Rush, M. M. (2000). Power, spirituality, and time from a feminist perspective: Correlates of sobriety in a study of sober female participants in Alcoholics Anonymous. Journal of the American Psychiatric Nurses Association, 6, 196-202.

Rush, M. M. (2002). Perceived social support: Dimensions of social interaction among sober female participants in Alcoholics Anonymous. Journal of the American Psychiatric Nurses Association, 8, 114-119.

Rychtarik, R., Connors, G., Dermen, K., \& Staciewicz, P. (2000). Medication to prevent relapse: An anonymous survey of member attitudes. Journal of Studies on Alcohol and Drugs. 61, 134-138.

Sanders, J. (2006). Women and the twelve steps of Alcoholics Anonymous: A gendered narrative. Alcoholism Treatment Quarterly, 24, 3-29.

Sanders, J. (2009). Women in Alcoholics Anonymous: Recovery and empowerment. London, United Kingdom: First Forum Press.

Sandoz, C. J. (1995). Gender issues in recovery from alcoholism. Alcoholism Treatment Quarterly, 1, $61-69$

Satre, D., Mertens, J. Areán, P., \& Weisner, C. (2004). Five-year alcohol and drug treatment outcomes of older adults versus middle-aged and younger adults in a managed care program. Addiction, 99, 1286-1297.

Satre, D., Mertens, J., \& Weisner, C. (2004). Gender differences in treatment outcomes for alcohol dependence among older adults. Journal of Studies on Alcohol, 65, 638-642.

Shuckit, M., Tipp, J., Smith T., \& Bucholz, K. (1997). Periods of abstinence following the onset of alcohol dependence in 1,853 men and women. Journal of Studies on Alcohol, 58, 581- 
589.

Schwartz, W. (1961). The social worker in the group. In B. Saunders (Ed.), New perspectives on services to groups: Theory, organization, practice. (pp. 7-29), New York: National Association of Social Workers.

Simpson, C. A., \& Tucker, J. A. (2002). Temporal sequencing of alcohol-related problems, problem recognition, and help-seeking episodes. Addictive Behaviors. 27, 659-674.

Slaymaker, V. J., \& Owen, P. L. (2006). Employed men and women substance abusers: Job troubles and treatment outcomes. Journal of Substance Abuse Treatment, 31, 347- 354.

Small, J., Curran, G., \& Booth, B. (2010). Barriers and facilitators for alcohol treatment for women: Are there more or less for rural women? Journal of Substance Abuse Treatment, 39, 1-13.

Smith, L. (1992). A descriptive study of alcohol-dependent women attending Alcoholics Anonymous, a regional council on alcoholism, and an alcohol treatment unit. Alcohol and Alcoholism, 27, 667-676.

Speiglman, R. (1994). Mandated AA attendance for recidivist drinking drivers: ideology, organization, and criminal justice practices. Addiction, 89, 859-868.

Stewart, S. H., \& Israeli, A. L. (2002). Substance abuse and co-occurring psychiatric disorders in victims of intimate violence. In C. Wekerle \& A. Walls (Eds.), The violence and addiction equation: Theoretical and clinical issues in substance abuse and relationship violence (pp. 98-122). New York: Brunner-Routledge.

Suire, J. G. \& Bothwell, R. K. (2006). The psychosocial benefits of Alcoholics Anonymous. The American Journal on Addictions, 15, 252-255.

Swett, C., \& Halpert, M. (1994). High rates of alcohol problems and history of physical and 
sexual abuse among women inpatients. American Journal of Drug Abuse, 20, 263-272.

Taylor, S. E. (2007). Social support. In H. S. Friedman \& R. C. Silver (Eds.). Foundations of health psychology (pp. 145-171). New York: Oxford University.

Terra, M. B., Barros, H., Stein, A., Figueira, I., Athayde, L., Spanemberg, L., et al. (2006). Does co-occurring social phobia interfere with alcoholism treatment adherence and relapse? Journal of Substance Abuse Treatment. 31, 403-409.

Thevos, A. K., Roberts, J., Thomas, S., \& Randall, C. (2000). Cognitive behavioral therapy delays relapse in female socially phobic Alcoholics. Addictive Behaviors, 25, 333-345

Timko, C. (2008). Outcomes of AA for special populations. In M. Galanter \& L.A. Kaskutas (Eds.). Recent Developments in Alcoholism. Research on Alcoholics Anonymous and Spirituality in Addiction Recovery. Volume 18. (pp. 373-392). New York: Springer.

Timko, C., DeBenedetti, Moos, \& Moos (2006). Predictors of 16-year mortality among individuals initiating help-seeking for an alcohol use disorder. Alcoholism: Clinical and Experimental Research, 30, 1711-1720.

Timko, C., Finney, J.W., \& Moos, R.H. (2005). The 8-year course of alcohol abuse: Gender differences in social context and coping. Alcohol: Clinical and Experimental Research, $29,612-621$.

Timko, C., Moos, R.H., Finney, J.W., \& Connell, E.G. (2002). Gender differences in helputilization and the 8-year course of alcohol abuse. Addiction, 97,877-889.

Timko, C., Moos, R., Finney, J., \& Lesar, M. (2000). Long-term outcomes of alcohol use disorders: comparing untreated individuals with those in Alcoholics Anonymous and formal treatment. Journal of Studies on Alcohol and Drugs. 61, 529 - 540.

Timko, C., Moos, B., \& Moos, R. (2009). Gender differences in 16-year trends in assault- and 
police-related problems due to drinking. Addictive Behaviors, 34, 744-750.

Tomasson, K., \& Vaglum, P. (1998). Psychiatric comorbidity and aftercare among alcoholics: A prospective study of a nationwide sample. Addiction, 93, 423-431.

Tonigan, S., Book, S., Pagano, M., Randall, P., Smith, J., \& Randall, C. (2010). 12-step therapy and women with and without social phobia: A study of the effectiveness of 12-step therapy to facilitate AA engagement. Alcoholism Treatment Quarterly, 28, 151-162.

Tonigan, S., Connors, G., \& Miller, W, (1996). Alcoholics Anonymous Involvement (AAI) scale: Reliability and norms. Psychology of Addictive Behaviors, 10, 75-80.

Tonigan, S., Miller, W., \& Schermer, C. (2002). Atheists, agnostics and Alcoholics Anonymous. Journal on the Study of Alcohol and Drugs. 63, 534-541.

Tonigan, S., Toscova, R., \& Miller, W. (1995). Meta-analysis of the literature on Alcoholics Anonymous: Sample and study characteristics moderate findings. Journal of Studies on Alcohol, 57, 65-72.

Tucker, J., \& Gladsjo, J. (1993). Help-seeking and recovery by problem drinkers: Characteristics of drinkers who attended Alcoholics Anonymous or formal treatment or who recovered without assistance. Addictive Behaviors, 18, 529-542.

Ullman, S.E., \& Najdowksi, C.J. (2010). Alcohol-related help seeking in problem drinking women sexual assault survivors. Substance Use and Misuse, 45, 341-353.

Vannicelli, M. (1986). Treatment considerations. In NIAAA Research Monograph 16. Women and Alcohol: Health-Related Issues, DHHS, 130-153.

Weisner, C., Greenfield, T., \& Room, R. (1995). Trends in the treatment of alcohol problems in the US general population, 1979 through 1990. American Journal of Public Health, 85, $55-60$. 
Weisner, C., Ray, G., Mertens, J., Satre, D., \& Moore, C. (2003). Short-term alcohol and drug treatment outcomes predict long-term outcome. Drug and Alcohol Dependence, 71, 281294.

Weiss, R. D., Griffin, M., Gallop, R., Luborsky, L., Siqueland, L., Frank, A., et al. (2000). Predictors of self-help group attendance in cocaine dependent patients. Journal on the Studies of Alcohol and Drugs, 61, 714-719.

Westermeyer, J., Myott, S., Aarts, R., \& Thuras, P. (2001). Self-help strategies among patients with substance use disorders. The American Journal on Addictions, 10, 249-257.

Wiechelt, S., \& Sales, E. (2001). The role of shame in women's recovery from alcoholism: The impact of child sexual abuse. Journal of Social Work Practice in the Addictions, 1, 101116.

Wilkie, D. (1994). Women and alcoholism: How a male-as-norm bias affects research, assessment, and treatment. Health and Social Work, 19, 29-35.

Wilsnack, S. C. (1982). Alcohol abuse and alcoholism in women. In Pattison, E., and Kaufman, E. (Eds). Encyclopedic Handbook of Alcoholism. New York: Gardner Press, pp. 718-735.

Wilsnack, S.C., Vogeltanz, N. D., Klassen, A. D., Harris, T. R. (1997). Childhood sexual abuse and women's substance abuse: national survey findings. Journal of Studies on Alcohol, 58, 264-271.

Wilsnack R., \& Wilsnack, S. (1997). Gender and alcohol: Individual and social perspectives. New Brunswick, NJ: Rutgers University Press.

Winters, K. C., Stinchfield, R., Weller, C., \& Latimer, W. (2000). The effectiveness of the Minnesota Model Approach in the treatment of adolescent drug abusers. Addiction, 95, $601-612$ 
Witbrodt, J., \& Romelsjo, A. (2010). Gender differences in mutal-help attendance 1 year after treatment: Swedish and US samples. Journal of Studies on Alcohol and Drugs, 71, 125135.

Witherspoon, K., \& Richardson, A. (2006). Sisters in support together against substances: An alcohol abuse prevention group for Black women. Journal of Ethnicity in Substance Abuse, 5, 51-62.

Zemore, S. E. (2004). Helping, Spirituality and Alcoholics Anonymous in Recovery. Journal on the Study of Alcohol and Drugs, 65, 383-391.

Zemore, S., \& Kaskutas, L. (2008). 12-step involvement and peer helping in day hospital and residential programs. Substance Use and Misuse, 43, 1882-1903.

Zemore, S., Mulia, N., Ye, Y., Borges, G., \& Greenfield, T. (2009). Gender, acculturation, and other barriers to alcohol treatment utilization among Latinos in three National Alcohol Surveys. Journal of Substance Abuse Treatment, 36, 446-456. 